\title{
Overview of Propulsion Controls and Diagnostics Research at NASA Glenn
}

Sanjay Garg

Glenn Research Center, Cleveland, Ohio 


\section{NASA STI Program . . . in Profile}

Since its founding, NASA has been dedicated to the advancement of aeronautics and space science. The NASA Scientific and Technical Information (STI) program plays a key part in helping NASA maintain this important role.

The NASA STI Program operates under the auspices of the Agency Chief Information Officer. It collects, organizes, provides for archiving, and disseminates NASA's STI. The NASA STI program provides access to the NASA Aeronautics and Space Database and its public interface, the NASA Technical Reports Server, thus providing one of the largest collections of aeronautical and space science STI in the world. Results are published in both non-NASA channels and by NASA in the NASA STI Report Series, which includes the following report types:

- TECHNICAL PUBLICATION. Reports of completed research or a major significant phase of research that present the results of NASA programs and include extensive data or theoretical analysis. Includes compilations of significant scientific and technical data and information deemed to be of continuing reference value. NASA counterpart of peer-reviewed formal professional papers but has less stringent limitations on manuscript length and extent of graphic presentations.

- TECHNICAL MEMORANDUM. Scientific and technical findings that are preliminary or of specialized interest, e.g., quick release reports, working papers, and bibliographies that contain minimal annotation. Does not contain extensive analysis.

- CONTRACTOR REPORT. Scientific and technical findings by NASA-sponsored contractors and grantees.
- CONFERENCE PUBLICATION. Collected papers from scientific and technical conferences, symposia, seminars, or other meetings sponsored or cosponsored by NASA.

- SPECIAL PUBLICATION. Scientific, technical, or historical information from NASA programs, projects, and missions, often concerned with subjects having substantial public interest.

- TECHNICAL TRANSLATION. Englishlanguage translations of foreign scientific and technical material pertinent to NASA's mission.

Specialized services also include creating custom thesauri, building customized databases, organizing and publishing research results.

For more information about the NASA STI program, see the following:

- Access the NASA STI program home page at http://www.sti.nasa.gov

- E-mail your question to help@sti.nasa.gov

- Fax your question to the NASA STI Information Desk at 443-757-5803

- Phone the NASA STI Information Desk at 443-757-5802

- Write to: STI Information Desk NASA Center for AeroSpace Information 7115 Standard Drive Hanover, MD 21076-1320 


\section{Overview of Propulsion Controls and Diagnostics Research at NASA Glenn}

\section{Sanjay Garg}

Glenn Research Center, Cleveland, Ohio

Prepared for the

48th Joint Propulsion Conference and Exhibit

cosponsored by the AIAA, ASME, SAE, and ASEE

Atlanta, Georgia, July 30-August 1, 2012

National Aeronautics and

Space Administration

Glenn Research Center

Cleveland, Ohio 44135 


\section{Acknowledgments}

The author will like to thank all the members of the Controls and Dynamics Branch for their enthusiasm and initiative in performing the research documented in this paper, and for providing the graphics and information for the paper. The Branch members including civil servants and contractors are: Rachael Bis, Joseph Connolly, Amy Chicatelli, Jeff Csank, Dennis Culley, John DeLaat, Christopher Fulton, Ten-Huei Guo, George Kopasakis, Jonathan Litt, James Liu, William Maul, Ryan May, Kevin Melcher, Daniel Paxson, Joseph Saus, Donald Simon, Shane Sowers, Thomas Stueber, Randy Thomas and Edmond Wong. The author will also like to thank the various NASA program/project managers who have supported these research efforts.

This report contains preliminary findings, subject to revision as analysis proceeds.

Trade names and trademarks are used in this report for identification only. Their usage does not constitute an official endorsement, either expressed or implied, by the National Aeronautics and Space Administration.

Level of Review: This material has been technically reviewed by technical management.

Available from

NASA Center for Aerospace Information 7115 Standard Drive

Hanover, MD 21076-1320
National Technical Information Service 5301 Shawnee Road Alexandria, VA 22312 


\title{
Overview of Propulsion Controls and Diagnostics Research at NASA Glenn
}
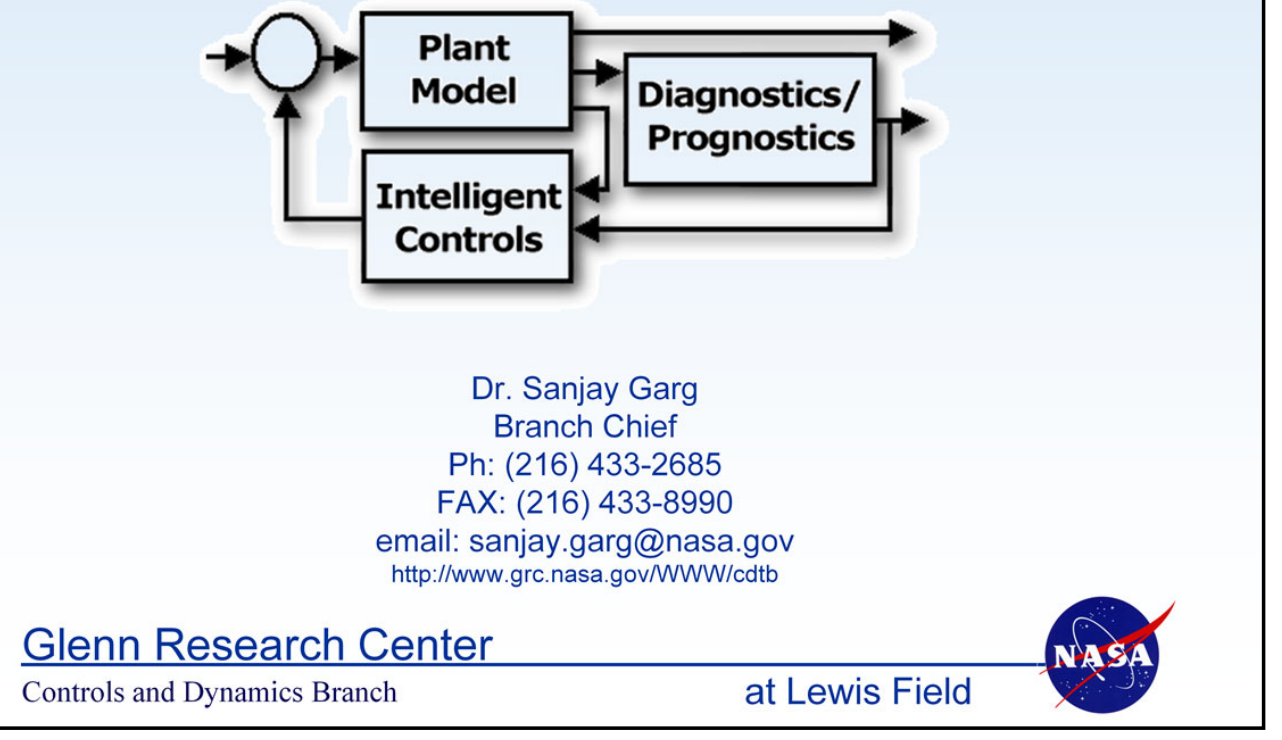

\begin{abstract}
With the increased emphasis on aircraft safety, enhanced performance and affordability, and the need to reduce the environmental impact of aircraft, there are many new challenges being faced by the designers of aircraft propulsion systems. The Controls and Dynamics Branch (CDB) at NASA (National Aeronautics and Space Administration) Glenn Research Center (GRC) in Cleveland, Ohio, is leading and participating in various projects in partnership with other organizations within GRC and across NASA, the U.S. aerospace industry, and academia to develop advanced controls and health management technologies that will help meet these challenges through the concept of an Intelligent Engine. CDB conducts propulsion control and diagnostics research in support of various programs and projects under the NASA Aeronautics Research Mission Directorate and the Human Exploration and Operations Mission Directorate. The paper first provides an overview of the various research tasks in CDB relative to the NASA programs and projects, and briefly describes the progress being made on each of these tasks. The discussion here is at a high level providing the objectives of the tasks, the technical challenges in meeting the objectives and most recent accomplishments. References are provided for each of the technical tasks for the reader to familiarize themselves with the details.
\end{abstract}




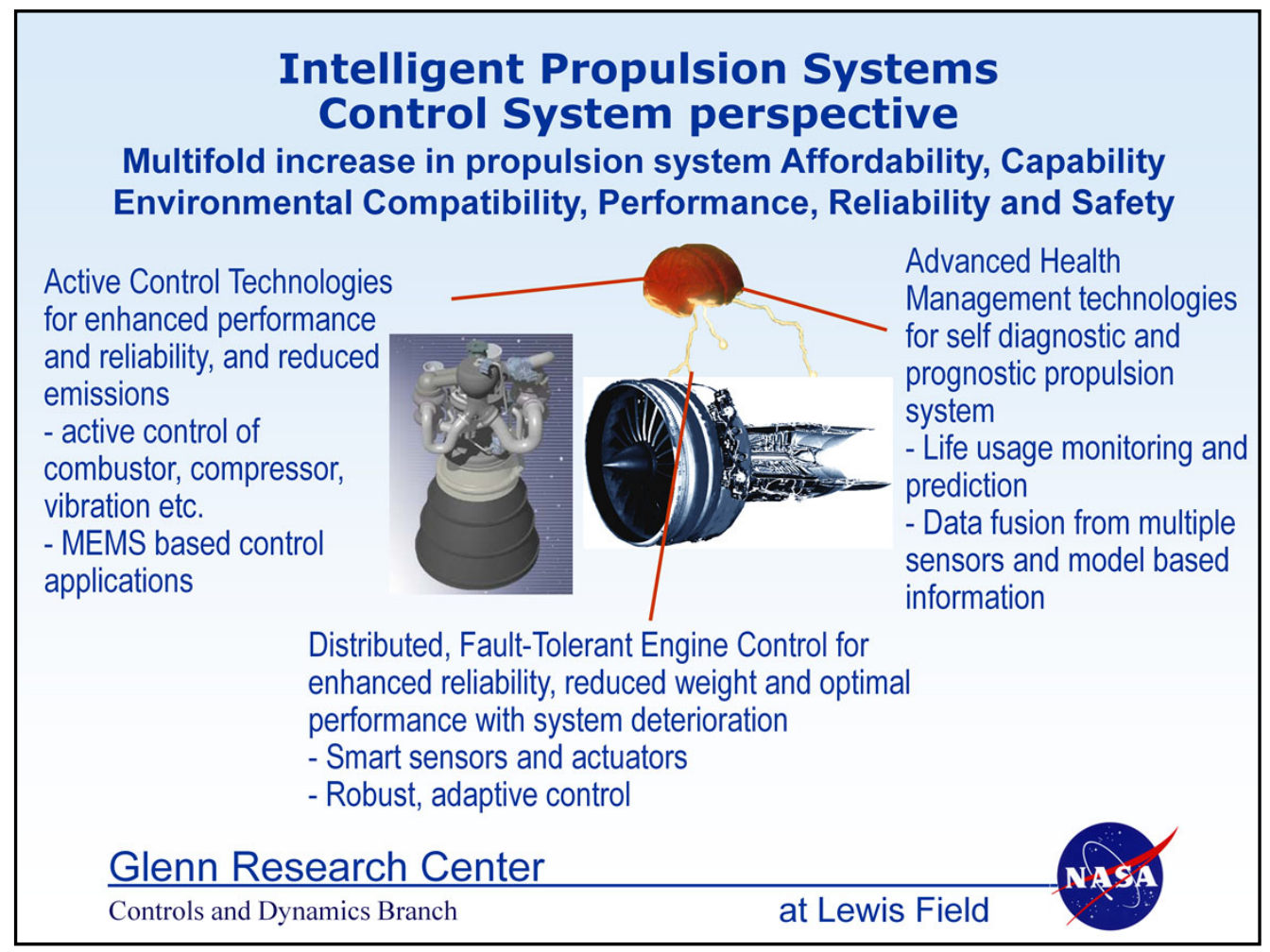

\section{Intelligent Propulsion Systems-Control System Perspective}

The control system enabling technologies for Intelligent Propulsion Systems are show above. These can be organized into three broad categories-active component control, advanced health management, and distributed fault tolerant control.

Engine components such as combustors, fans and compressors, inlets, nozzles etc. are designed for optimum component performance within some overall system constraints and the control design problem has been to transition the operating point of the engine from one set point to another in a most expedient manner without compromising safety. With the advancements in information technologies, the component designers are beginning to realize the potential of including active control into their component designs to help them meet more stringent design requirements and the need for affordable and environment friendly propulsion systems.

The need to have more reliable and safe engine service, to quickly identify the cause of current or future performance problems and take corrective action, and to reduce the operating cost requires development of advanced diagnostic and prognostic algorithms. The objective for this technology development is to maximize the "on wing" life of the engine and to move from a schedule based maintenance system to a condition based system.

Implementation of these concepts requires advancements in the area of robust and adaptive control synthesis techniques, and development of new hardware such as smart sensors and actuators. Attention will also need to be paid to integration of the active component control and diagnostics technologies with the control of the overall engine system which will require moving from the current analog control systems to distributed control architectures.

Ref: Garg, S., "NASA Glenn Research in Controls and Diagnostics for Intelligent Aerospace Propulsion Systems," 2005 AIAA Infotech@Aerospace Conference, Arlington, VA, October 2005. 


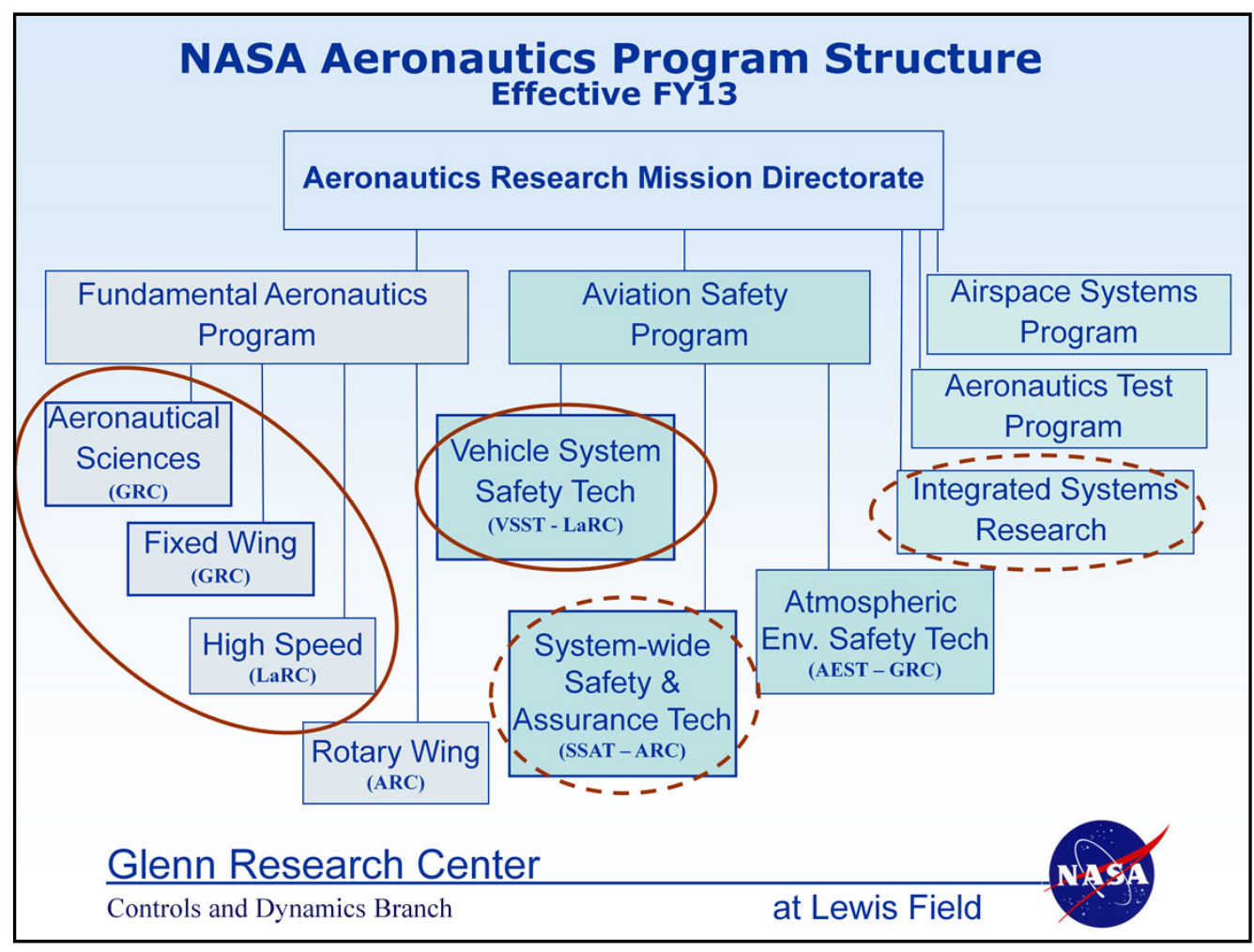

\section{NASA Aeronautics Program Structure (Effective FY13)}

The NASA Aeronautics Research Mission program structure consists of five major programs: Fundamental Aeronautics (FAP), Aviation Safety (ASP), Airspace Systems, Aeronautics Test, and Integrated Systems Research (ISRP), with each of these programs having 2 or more projects. The CDB activities are primarily in the various projects under FAP and ASP, with a small participation in the Environmentally Responsive Aviation (ERA) project of ISRP.

The Fundamental Aeronautics Program (FAP) went through a reorganization in FY12, and the projects listed are as the program will be implemented in FY13 (Fiscal Year 2013 - the government fiscal year is from October 1 to September 30). For FY12, the FAP consisted of four projects-Subsonic Fixed Wing (SFW), Subsonic Rotary Wing (SRW), Supersonics (SUP) and Hypersonics (HYP). The FAP was restructured to have the 4 projects shown in the chart for FY13 onwards-HYP project was eliminated with some of the critical hypersonics research work combined with a relevant supersonics research into the new High Speed (HS) project; the Aeronautical Sciences (AS) project was created to focus investment in fundamental technology and tools development which are crosscutting, i.e., have applicability across a wide range of flight speeds; and the Subsonic Fixed Wing (SFW) and Subsonic Rotary Wing (SRW) projects were renamed the Fixed Wing (FW) and Rotary Wing (RW) projects, respectively, with content focused on technologies that are directly relevant to the objectives of these projects.

The Aviation Safety Program (ASP) went through a restructuring in 2010 and the current program structure is reflected in the chart. CDB has a significant activity under the VSST (Vehicle System Safety Technologies) project of ASP with a small task under the SSAT (System-wide Safety \& Assurance Technology) project. Additionally CDB does research on engine icing detection and mitigation under the VSST project which is a collaborative effort with the AEST (Atmospheric Environment and Safety Technologies) project.

Detailed information about the ARMD programs is available at: http://www.aeronautics.nasa.gov/programs.htm 


\title{
CDB Tasks Under NASA Aeronautics Research
}

\author{
Fundamental Aeronautics Program (FAP) \\ - Distributed Engine Control - SFW -> AS \\ - Model-Based Engine Control - SFW -> AS \\ - Pressure Gain Combustion - SFW -> AS \\ - Dynamic Systems Analysis - FW new start \\ - Active Combustion Control - SUP -> AS \\ - Aero-Propulso-Servo-Elasticity - SUP -> HS \\ - TBCC Dynamic Modeling and Control - HYP -> X \\ Aviation Safety Program \\ - Gas Path Health Management - VSST \\ - Integrated Resilient Propulsion Control - VSST - complete \\ - Robust Propulsion Control - VSST \\ - Run-time Validation of Complex Systems - SSAT
}

\section{Glenn Research Center}

\section{CDB Tasks Under NASA Aeronautics Research}

The Controls and Dynamics Branch (CDB) tasks under the NASA Aeronautics Research Program, and the program/project that support these tasks, are listed above. The task relationships to projects, as of August 2012, is briefly discussed below, and the tasks are discussed in a little more detail in the rest of the paper.

\section{Fundamental Aeronautics Program}

Distributed Engine Control and Model Based Engine Control : These efforts are currently under the SFW project, but will transition to the AS project in FY13 as part of the Controls sub-project.

Pressure Gain Combustion: This effort is currently under the SFW project. It is expected to continue under the Combustion sub-project of AS project.

Dynamic Systems Analysis: This is a new start in FY13 under the MDAO (Multidisciplinary Analysis and Optimization) sub-project of the FW project. No detail is provided on this task in the paper since this effort has not yet started.

Active Combustion Control: Major effort under this task will transition from the SUP project to the AS project in FY13 under the Combustion sub-project. Small efforts will continue in support of the ERA project under the ISRP. Also a small effort will support technology maturation under the new Fixed Wing project.

Aero-Propulso-Servo-Elasticity: This effort, currently under the SUP project, will continue under the new High Speed project in FY13.

Turbine Based Combined Cycle (TBCC) Dynamic Modeling and Control: This effort will be discontinued in FY13 with the cancellation of the HYP project. The TBCC leadership is in discussions with Army and Air Force to provide support to their Hypersonics Research programs.

\section{Aviation Safety Program}

Gas Path Health Management: This effort will continue under the VSST project.

Integrated Resilient Propulsion Control: This effort on enhanced engine response control was carried over into VSST from the previous IRAC (Integrated Resilient Aircraft Control) project and is now complete.

Robust Propulsion Control: This effort will continue in VSST as part of addressing the "Loss of Control" technical challenge.

Run-time Validation of Complex Systems: This effort will continue under the VVFCS (Verification and Validation of Flight Critical Systems) element of SSAT project. 


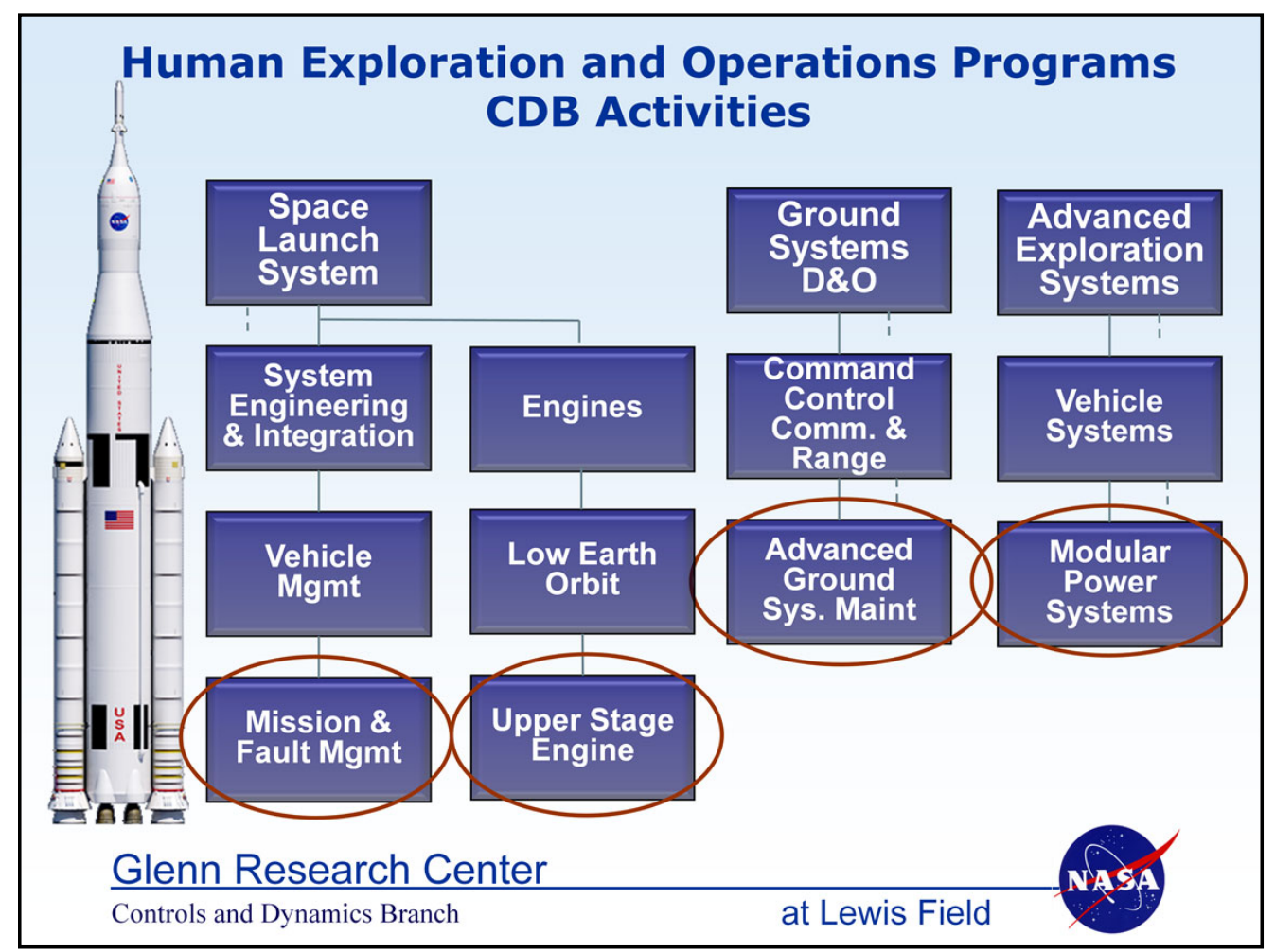

\section{Human Exploration and Operations Programs_-CDB Activities}

In 2009, the NASA Explorations Systems program was restructured to reflect the priorities of the new administration. The Constellation Program was cancelled and replaced by the Explorations Systems Development program which includes the Orion Multi-Purpose Crew Vehicle (MPCV), Space Launch System (SLS), and Ground Systems Development and Operation (GSDO) programs. CDB has tasks in system modeling and fault management technology development under the SLS and GSDO programs. Additionally, the previous Exploration Systems Technology program was reorganized as the Advanced Exploration Systems (AES) program. CDB has a small activity ongoing under one of the projects in the AES program.

For the SLS program, under the SEI (Systems Engineering and Integration) project, CDB is supporting various aspects of the Mission and Fault Management effort which is led by MSFC (Marshall Space Flight Center).These efforts are focused first on ensuring crew safety/survival and secondly on ensuring mission success. Under the Engines project of the SLS program, CDB is working in collaboration with MSFC and Pratt \& Whitney Rocketdyne to develop methods and system models to characterize the J-2X engine performance parameters from test data, and to ensure that the test-data used for such characterization is not faulty.

For the GSDO program, CDB is working with KSC (Kennedy Space Center) under the Advanced Ground Systems Maintenance element to develop functional fault models of the Cryogenics Testbed and selected ground support equipment subsystems, to be able to perform detection and isolation of subsystem faults and failures during testing and launch operations.

For the AES program, CDB is supporting the Modular Power Systems project and leading the development of a health management and control architecture for modular power systems, with elements of the architecture to be tested on system components.

Detailed information about the HEOMD programs is available at: http://www.nasa.gov/directorates/heo/home/index.html 


\section{Distributed Engine Control (DEC)}

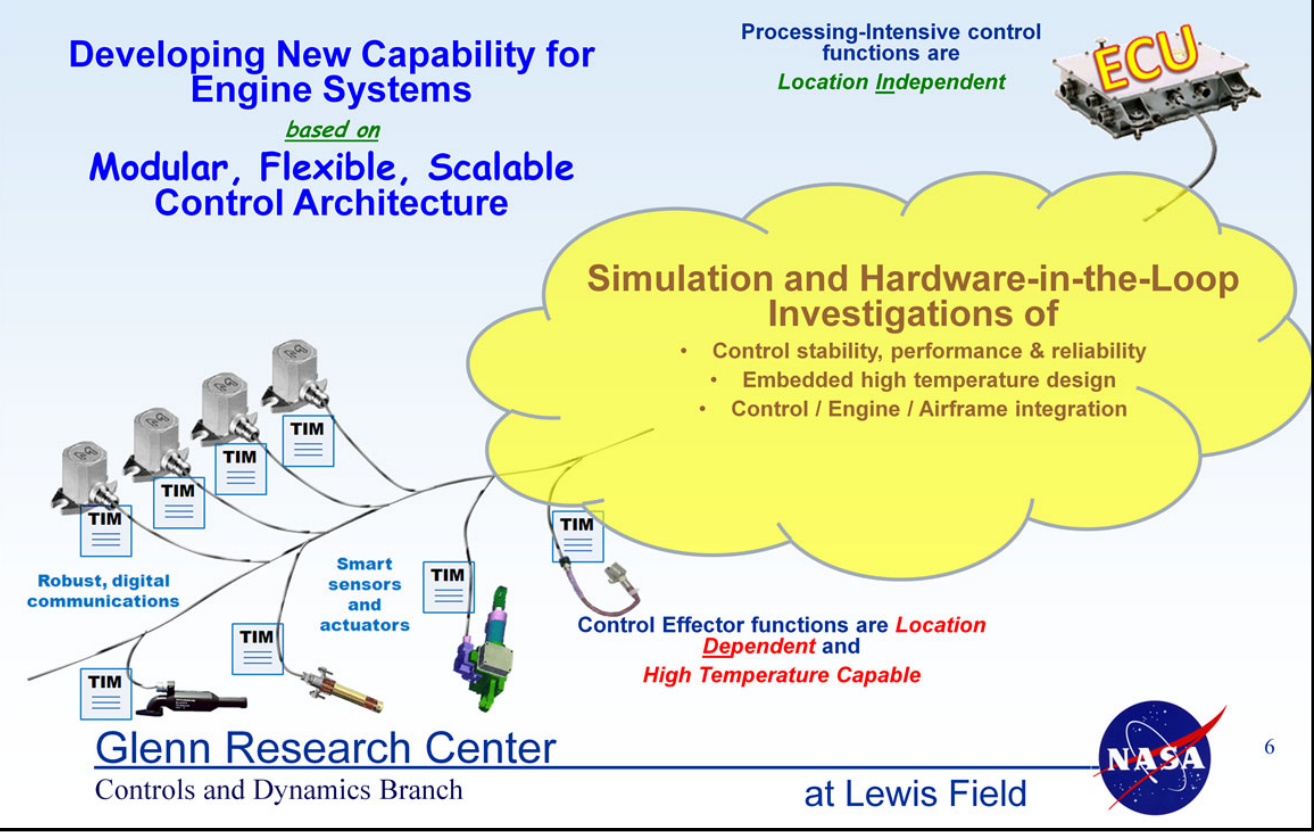

\section{Distributed Engine Control (DEC)}

Distributed (decentralized) engine control involves the development of multiple new technologies for implementation on the turbine engine system. One key requirement is to enable a modular architecture which allows the heavy processing capability critical for advanced control algorithms to be location independent. This preserves the ability of designers to use familiar commercially available processing components, capabilities, and tools. A digitally networked ECU (Engine Control Unit) can be located anywhere, even on the airframe, with minimal system impact.

This also requires that electronics be embedded in control components which must remain on the engine. For most of these components, high temperature electronics are critical to alleviate the weight impact of cooling electronics and for long term reliability. However, high temperature electronics are relatively primitive compared to commercially electronic components. This creates system constraints for control system operation and performance.

Distributed control on turbine engines requires an entirely new portfolio of technologies beyond high temperature electronics to be able to design, analyze, and optimize control systems for continued performance improvement of the turbine propulsion system. Capability to test and validate the operation of high temperature capable control components such as sensors and actuators requires development of new hardware-in-the-loop test capability. Research efforts include: analyzing the requirements for different data communication architectures for decentralized control; studying the impact of distributing the current functions of the Engine Control Unit among the various control components; performing reliability analysis of different architectures etc.

NASA GRC in collaboration with Air Force Research Lab and industry partners, through the Distributed Engine Control Working Group (DECWG), is conducting research on various technologies to enable distributed engine control.

Ref.:, Culley, D.E., "Transition in Gas Turbine Control System Architecture: Modular, Distributed and Embedded,” GT2010-23226, ASME Turbo Expo 2010, Glasgow, UK, June 14-18, 2010. 


\section{DEC Control Architecture and Requirements}

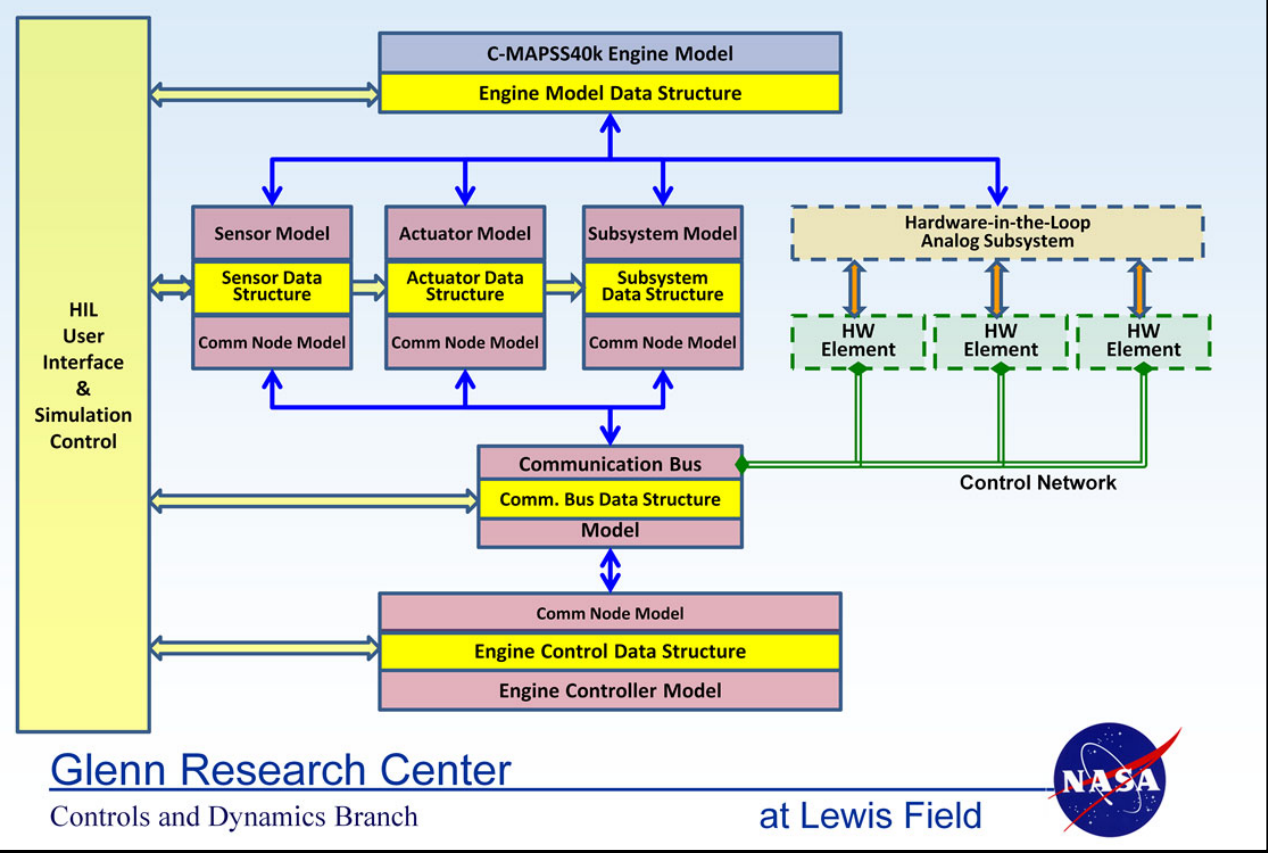

\section{DEC Control Architecture and Requirements}

The development of Hardware-in-the-Loop (HIL)capability for distributed engine control is critical for understanding how to best implement control architecture for various engine applications. It provides a means to analyze and quantify system performance in order to advance new technologies. NASA GRC is working with Rolls Royce Liberty Works to develop a HIL capability for distributed engine control research. This HIL environment will allow engineers to design control systems in simulation and then continue that development through hardware, all within a common environment.

The HIL system will use common simulation tools and develop libraries of modular control components. Each control component will be defined by its functional capability and interconnected to the larger system through a structured interface definition. This provides great flexibility and allows the system to be easily partitioned and scaled. The requirements of each system component can be defined and validated before proceeding to hardware development. When hardware is available, it can replace its simulated version and the system operated in hard realtime mode.

The diagram shows the rigidly structured interaction of each control module operating through well-defined interfaces (the vertical flow between components). The user interface is able to peer inside the simulated modules (the horizontal flow between data structures) to analyze exactly what is happening with the data flow inside of each modular element. Actual hardware components function exactly the same way but have less visibility because they are forced to communicate strictly through the communication interface.

The intention of the HIL system is to enable multiple organizations to interact in the requirement definition and design of control system components, and to provide the tools which can quantify the performance and system level benefits of advanced control technologies. 


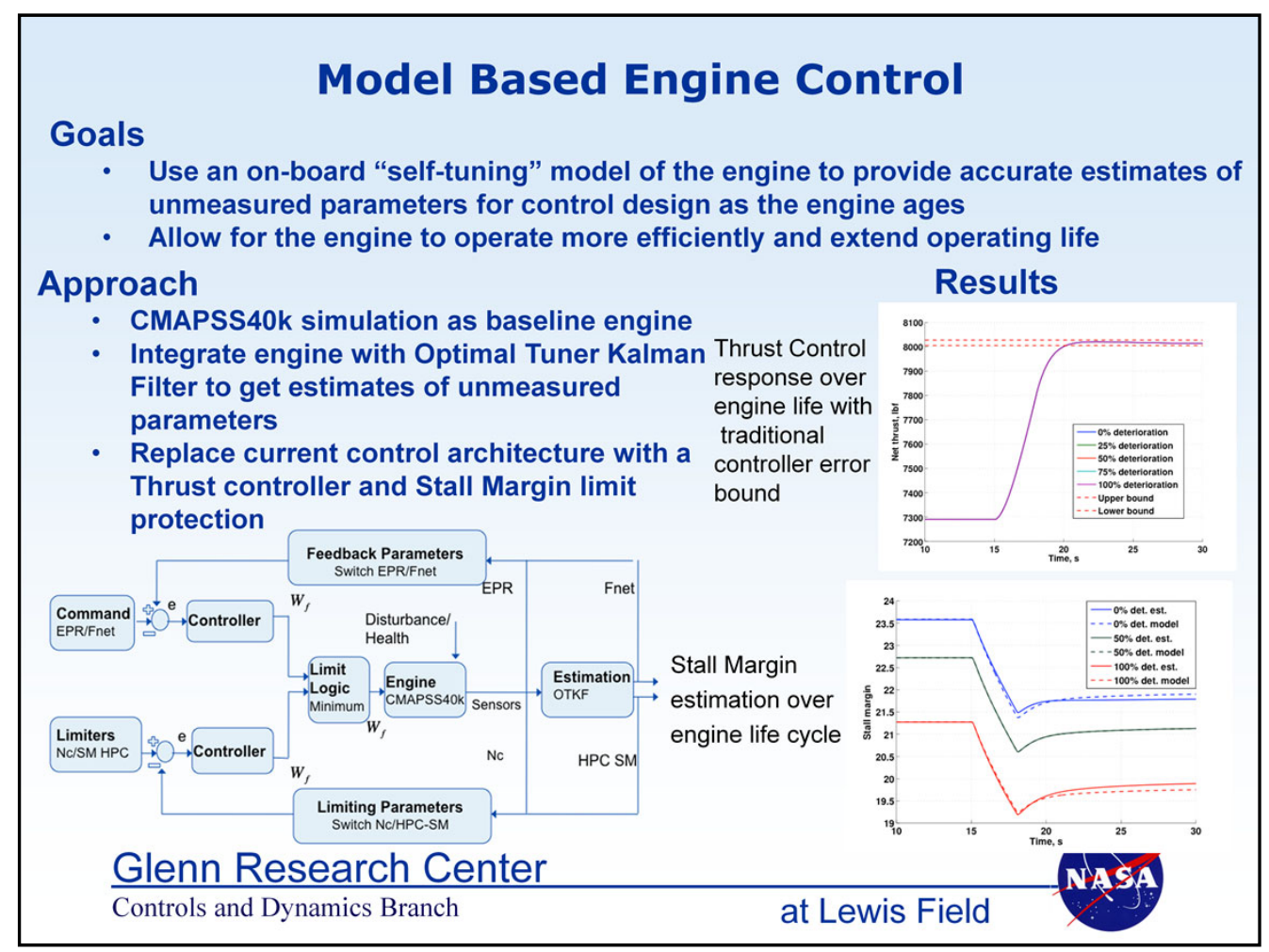

\section{Model Based Engine Control}

Model-based engine control (MBEC) is being developed as one of the advanced engine control system methodologies to improve turbofan engine performance and efficiency. In current engine control architectures, the typical design approach is to regulate a measurable variable such as fan shaft speed (Nf) or engine pressure ratio (EPR), which is strongly correlated with thrust. This is done since engine thrust is not a measurable parameter from typical on-board engine sensors. Additionally, limits on allowable fuel flow are imposed based on a conservative approach to maintain adequate stall margin and temperature margin for safe operation of the engine throughout its life.

MBEC will enable operation of an engine using a direct feedback of thrust providing the ability to have a tighter control of the main parameter of interest for engine performance at various deterioration levels throughout its life cycle or unexpected disturbances. In addition, MBEC will allow operation with less conservative safety margins, since all safety margins currently are designed to an end of life engine, whereas an on-board model can provide a more accurate margin for the actual condition of the flight engine. The reduction in the safety margins for newer engines will increase fuel efficiency, which links to the critical aeronautics research goals. Direct control of thrust will help maintain a tight bound on variations in the engine throttle to thrust response as the engine ages. The longer-term pay-off of this research is to have a personalized control for each specific engine, which adapts to the condition of the engine to not only maintain the most efficient operation throughout its lifetime but also increase the useful operating life.

Ref.: Connolly, J., "Model-Based Engine Control of a Commercial Class Turbofan Engine using an Optimal Tuner Approach," 48th AIAA/ASME/SAE/ASEE Joint Propulsion Conference \& Exhibit and 10th International Energy Conversion Engineering Conference Atlanta, GA, Jul-Aug. 30-1, 2012 


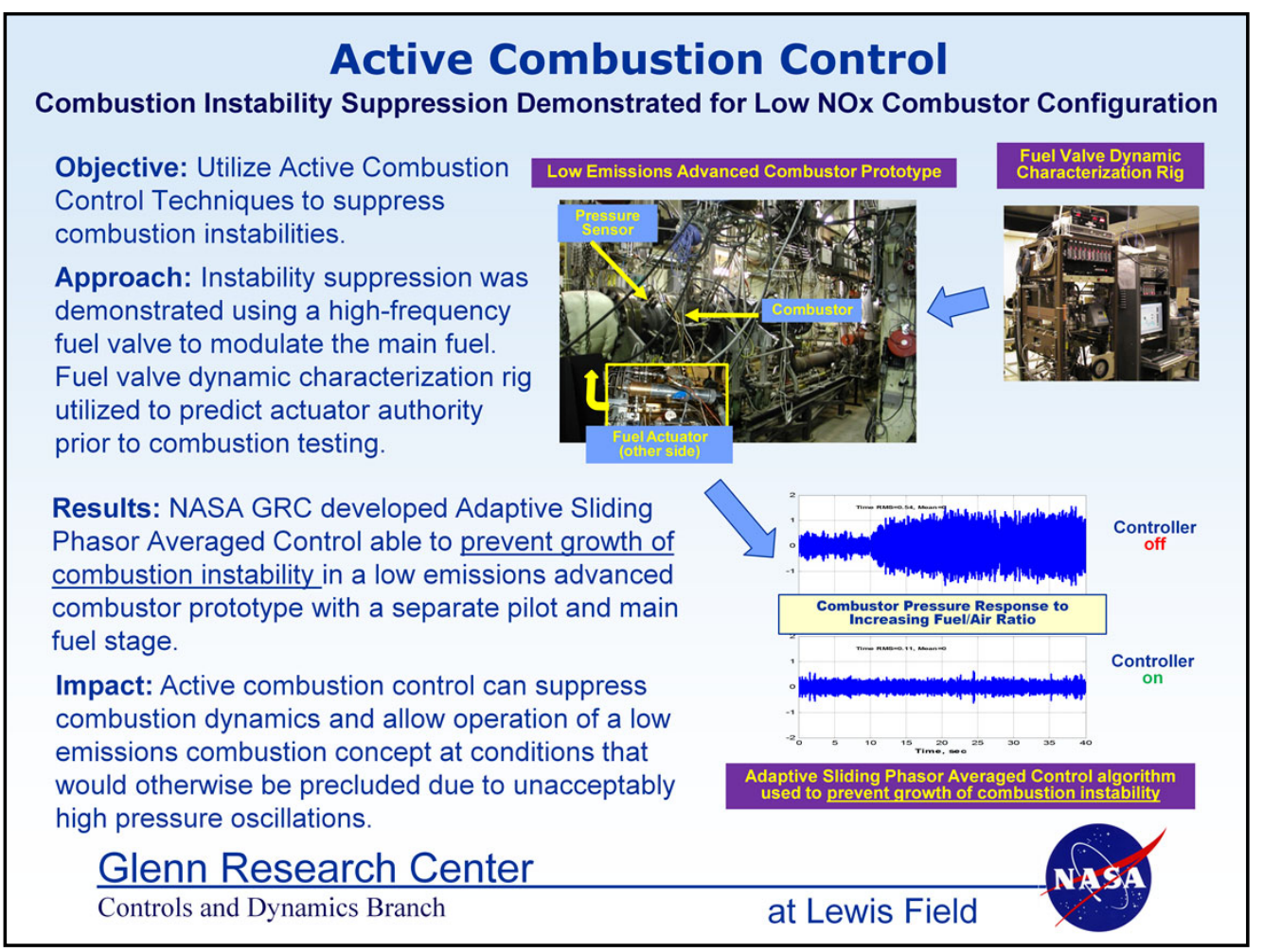

\section{Active Combustion Control-Combustion Instability Suppression Demonstrated}

Lean combustion concepts for aircraft engine combustors are prone to combustion instabilities. Mitigation of instabilities is an enabling technology for these low-emissions combustors. Prior research at NASA Glenn Research Center has demonstrated active control to suppress a high-frequency combustion instability in a combustor rig designed to emulate an actual aircraft engine instability experience with a conventional, rich-front-end combustor. The current effort is developing further understanding of the problem specifically as applied to future lean-burning, very low-emissions combustors.

A prototype advanced, low-emissions aircraft engine combustor with a combustion instability has been identified and previous work has characterized the dynamic behavior of that combustor prototype. The combustor exhibits thermo-acoustic instabilities that are related to increasing fuel flow and that potentially prevent full-power operation. A simplified, non-linear oscillator model and a more physics-based sectored 1-D dynamic model have been developed to capture the combustor prototype's instability behavior. Utilizing these models, the NASA Adaptive Sliding Phasor Average Control (ASPAC) instability control method has been updated for the low-emissions combustor prototype.

Active combustion instability suppression using the ASPAC control method has been demonstrated experimentally with this combustor prototype in a NASA combustion test cell operating at engine pressures, temperatures, and flows. A high-frequency fuel valve was utilized to perturb the combustor fuel flow. Successful instability suppression was shown using a dynamic pressure sensor in the combustor for controller feedback. Instability control was also shown with a pressure feedback sensor in the lower temperature region upstream of the combustor. It was also demonstrated that the controller can prevent the instability from occurring while combustor operation was transitioning from a stable, low-power condition to a normally unstable high-power condition, thus enabling the high-power condition.

Ref.: DeLaat, J.C.; Kopasakis, G.; Saus, J.R.; Chang, C.T.; Wey, C.: “Active Combustion Control for Aircraft GasTurbine Engines-Experimental Results for an Advanced, Low-Emissions Combustor Prototype" 50th AIAA Aerospace Sciences Meeting, Nashville, TN, January 2012. AIAA-2012-0783. 


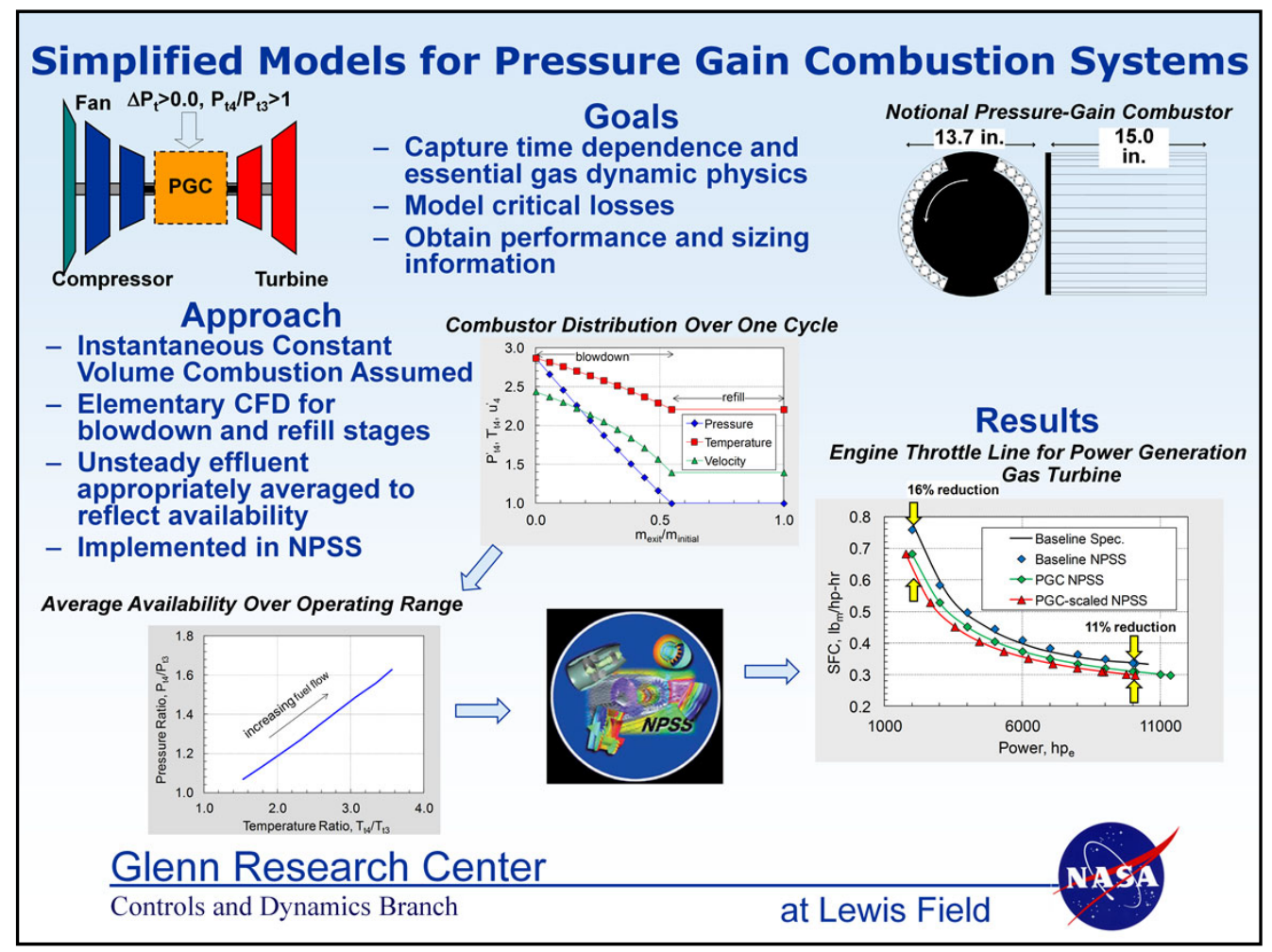

\section{Simplified Models for Pressure Gain Combustion Systems}

Pressure gain combustion (PGC) is being investigated for potential application to gas turbines. Here, the pressure rise (as opposed to a conventional combustor loss) yields higher engine thermal efficiency and specific power. In any potential application, system studies must be undertaken. These require component models which can generate meaningful performance predictions over a range of flight conditions and parameter variations. Furthermore, these models must compute solutions very quickly due to their being exercised over many parameters. This is a particular challenge for PGC devices which are fundamentally unsteady, and therefore result in time dependent limit cycle solutions rather than single, steady-state operating points. The modeling effort illustrated above has taken the least complex approach possible, while maintaining this essential time dependence. The project has produced several codes that close in approximately the time it takes to click a mouse, and which produce performance estimates consistent with higher fidelity CFD (Computational Fluid Dynamics) models.

Shown in the chart are a simple schematic of a pressure gain combustor in a gas turbine engine, and a notional combustor which was sized using the present model. The complete combustor is comprised of many smaller combustion chambers, each undergoing the same limit cycle. The model focuses on just one of these chambers. The center figure shows a typical limit cycle output from the model. Here the exit plane distribution of pressure, temperature, and velocity are shown (normalized by combustor entry conditions). At each operating point, such output is averaged to provide a single total pressure and temperature representing the equivalent steady performance at that operating point. A typical combustor performance map based on these averages is shown in the lower left. The unsteady model and averaging method have now been implemented in NASA's Numerical Propulsion System Simulation (NPSS) which allows the PGC component to be integrated with other gas turbine components into a complete engine simulation. A throttle line calculation (idle to max. power) is shown for a small power generation facility. Here, the baseline specific fuel consumption is shown as a function of shaft power (throttle setting) for the baseline engine and for the same engine with PGC. The reduction in SFC is quite impressive.

Ref.: Paxson, D. E., Kaemming, T. A., "Foundational Performance Analyses of Pressure Gain Combustion Thermodynamic Benefits for Gas Turbines," AIAA paper 2012-770, January, 2012 


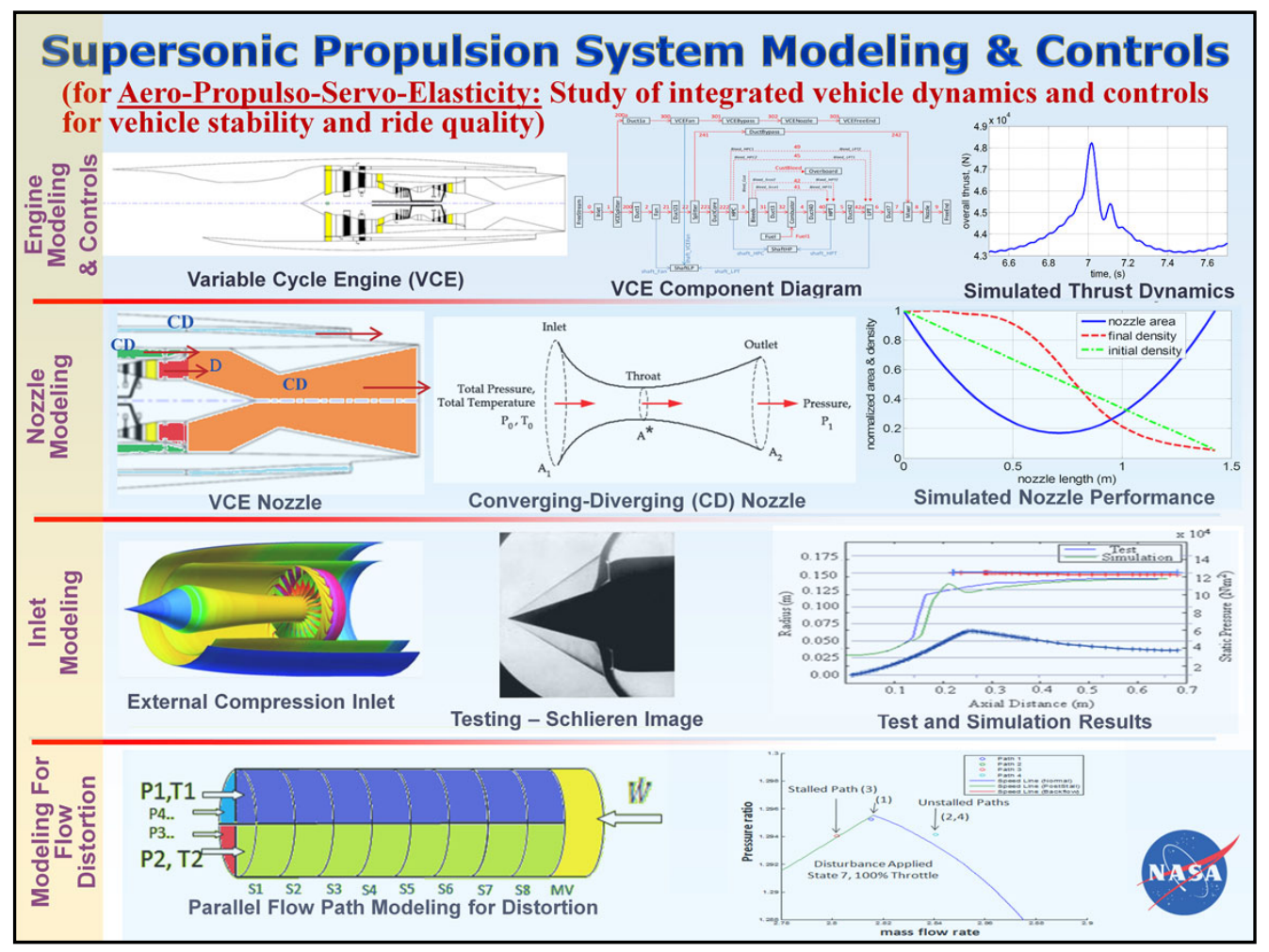

\section{Supersonic Propulsion System Modeling and Control}

For the NASA Supersonics, project, the overall objective is to perform the research to advance the technology so that the industry will be in position to develop supersonic cruise vehicles such as a civil transport. There are many technical challenges remaining for the supersonic vehicle technology development, such as sonic boom reduction for overland flight, emissions (NOx ) reduction, fuel efficiency, materials, control and handling qualities, etc.

The objective of the Aero-Servo-Elasticity (ASE) task and specifically the Aero-Propulso-Servo-Elasticity (APSE) task is to develop dynamic models for integrated propulsion and airframe systems and associated control designs to study overall vehicle performance, such as vehicle stability and vehicle ride quality as well as overall efficiency. The future supersonic transport vehicles are expected to be slender body with a highly flexible structure. Initial studies have shown that there is a potential for significant coupling between the flexible modes and the engine dynamics which can result in unacceptable ride qualities. Therefore the objective of the overall APSE effort is to develop higher fidelity propulsion system dynamics, understand the coupling issues with flexible modes and design conceptual control logic to mitigate the effects of such coupling. The types of modeling employed are volume gas dynamics with component performance characteristics - lump and stage-by-stage, Computational Fluid Dynamics (CFD), and parallel flow path modeling. Control designs involve feedback controls loop shaping, and engine schedules for compressor Inlet Guide Vanes, fan bypass, and exit nozzle area.

In the chart, the first row shows the baseline variable cycle engine diagram, components that have been modeled with associated control designs, and an example thrust response due to atmospheric turbulence. The second row shows the variable geometry multi-flow path nozzle design with sonic boom abatement, initial CFD modeling and responses. The third row shows the inlet concept design, a test Schlieren image, and modeling results. The forth row shows a diagram for a Parallel flow path stage-by-stage compressor modeling and an example response of stage 7 at 100 percent speed under a certain flow distortion signature.

Ref.: Connolly, J.W., Kopasakis, G., Paxson, D.E., Stuber, E., and Woolwine, K., "Nonlinear Dynamic Modeling and Controls Development for Supersonic Propulsion System Research ," 47th Joint Propulsion Conference and Exhibit; 31 Jul. - 3 Aug. 2011; San Diego, CA. 


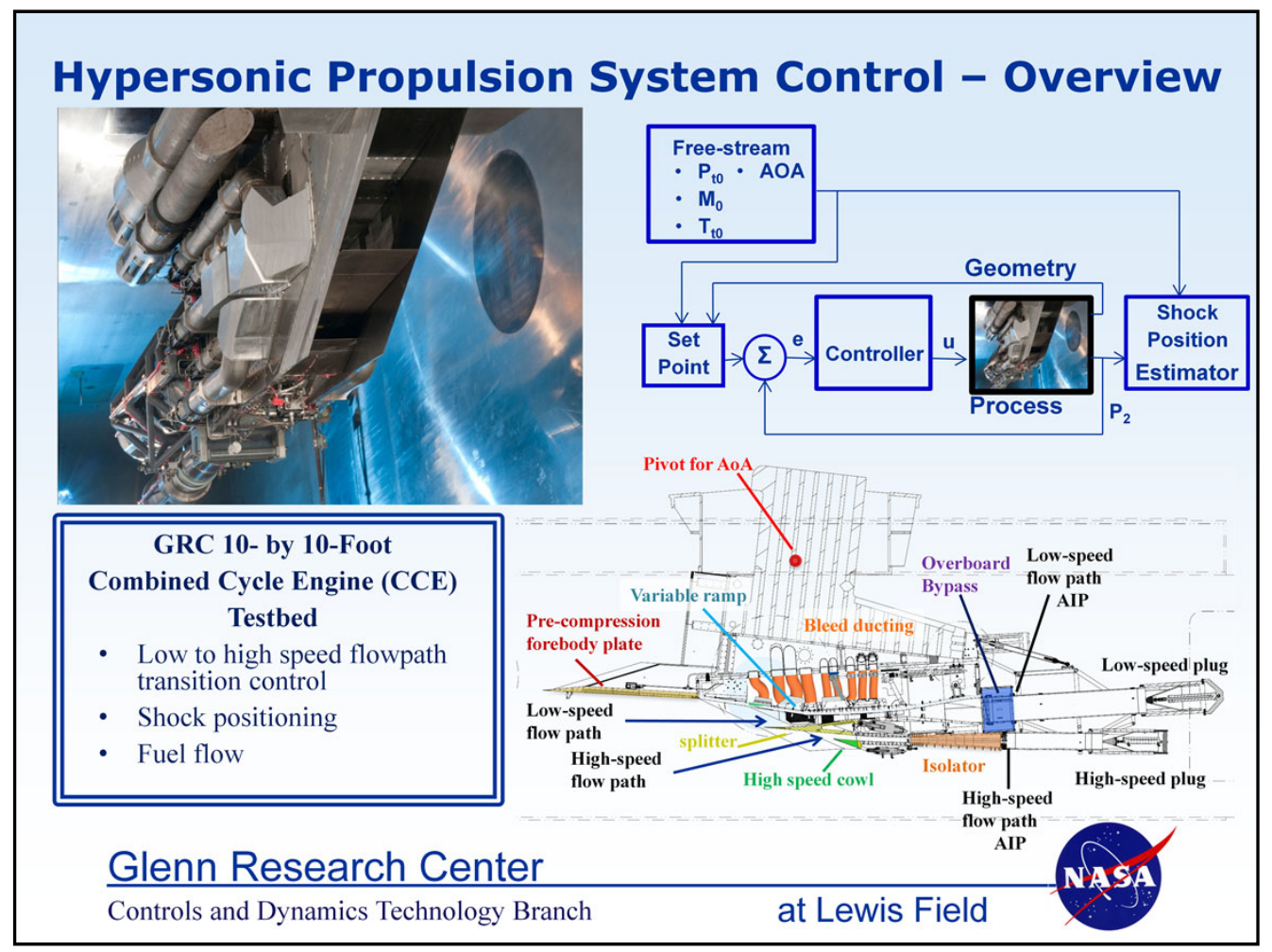

\section{Hypersonic Propulsion System Control-Overview}

Control research for a Turbine Based Combined Cycle (TBCC) propulsion system is being conducted as part of the Hypersonic project under the NASA Fundamental Aeronautics Program. The ongoing work is to develop tools to aid the design of control algorithms to manage a TBCC airbreathing propulsion system during the critical operating period when the propulsion system transitions from one cycle to another, referred to as mode transition. The first step underway is developing computational models for each component of the propulsion system. These component models will be collected under a common programming format for an overall propulsion system computational model.

Current research is focused on developing the computational models to simulate an airbreathing TBCC propulsion system inlet. The TBCC inlet aerodynamic design being modeled is that of the Combined-Cycle Engine (CCE) Testbed. The CCE Testbed is a large-scale hardware model of an aerodynamic design that was verified in a smallscale screening experiment. The CCE Testbed has been designed for experiments in the NASA GRC 10- by 10-Foot Supersonic Wind Tunnel (SWT). This mixed compression inlet system is suitable for experiments focusing on mode transition studies. The modeling approach includes employing existing state-of-the-art simulation codes, developing new dynamic simulations, and performing system identification experiments on the CCE Testbed in the SWT. The developed computational models will be available for control studies prior to hardware buildup. The system identification experiments will characterize the necessary dynamics to be represented in the models for control design. The primary objective for the CCE Testbed is to experimentally investigate and develop methods of mode transition for a TBCC type propulsion system. Ideally, these hardware tests will result in a demonstration of an inlet system capable of maintaining inlet operability and safety margins with maximum performance through all flight conditions including mode transition. The CCE large scale inlet testing Phase I and Phase II have been completedPhase I focused on quantifying inlet performance for the transition Mach Nos., while Phase II focused on conducting System Identification experiments to collect data to develop control models of the inlet.

Ref.: Stueber, T.J., Vrnak, D.R., Le, D.K., and Ouzts, P.J., "Control Activity in Support of NASA TBCC Research," NASA TM-2010-216109, January, 2010. 


\section{Hypersonic Propulsion System Control - HiTECC}

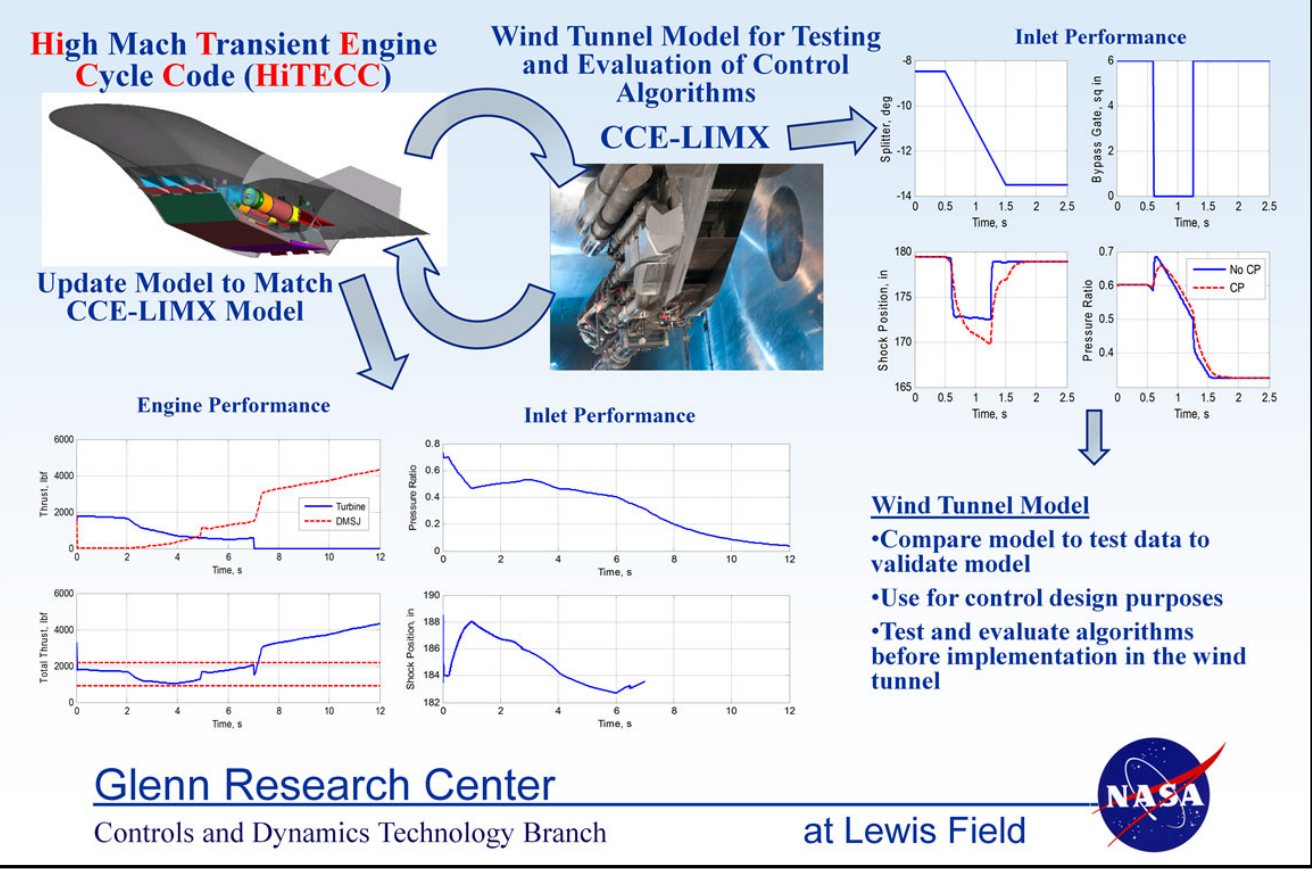

\section{Hypersonic Propulsion System Control-HiTECC}

The High Mach Transient Engine Cycle Code, HiTECC, initially developed by Spiritech Advanced Products, Inc., via a NASA NRA (NASA Research Announcement) award, is a collection of propulsion system simulation components configured to simulate a complete turbine based combined cycle (TBCC) propulsion system. The HiTECC simulation includes code for the following components: turbine engine and inlet, dual-mode scramjet (DMSJ) and inlet, and an aft nozzle. Furthermore, HiTECC is coded to include heat transfer models, fuel flow models, hydraulics models, kinematic models, and a control system. The original HiTECC configuration was a simulation for a general propulsion system design and the modular components allow for propulsion system changes. This feature enables the use of HiTECC to consider alternate inlet designs, DMSJs, or other turbine engine models.

Since HiTECC was designed as a propulsion system simulation toolbox that employs the MathWorks, Inc. MATLAB software as a programming platform, the geometry, actuators, and control systems can be easily modified. This flexibility made the HiTECC simulation software readily modifiable to suitably represent the CCELIMX as it was configured in the GRC 10- by 10-Foot SWT.

The HiTECC wind tunnel model has the simulation geometry defined to match the CCE-LIMX within \pm 2 percent error with respect to the actual hardware geometry. This configuration includes mass-flow plugs and cold pipe assemblies, instead of a turbine engine or DMSJ, representative of the CCE-LIMX experiments. Furthermore, this version of the HiTECC package did not need the components that simulate a thermal or fuel management system. Configured in this manner, the HiTECC wind tunnel model serves as a computational test bed capable of testing mode transition procedures and control algorithms.

Csank, J.T., Stueber, T.J., "A Turbine Based Combined Cycle Engine Inlet Model and Mode Transition Simulation Based on HiTECC Tool," $48^{\text {th }}$ AIAA/ASME/SAE/ASEE Joint Propulsion Conference \& Exhibit, July 30 - August 1, 2012, Atlanta, GA 


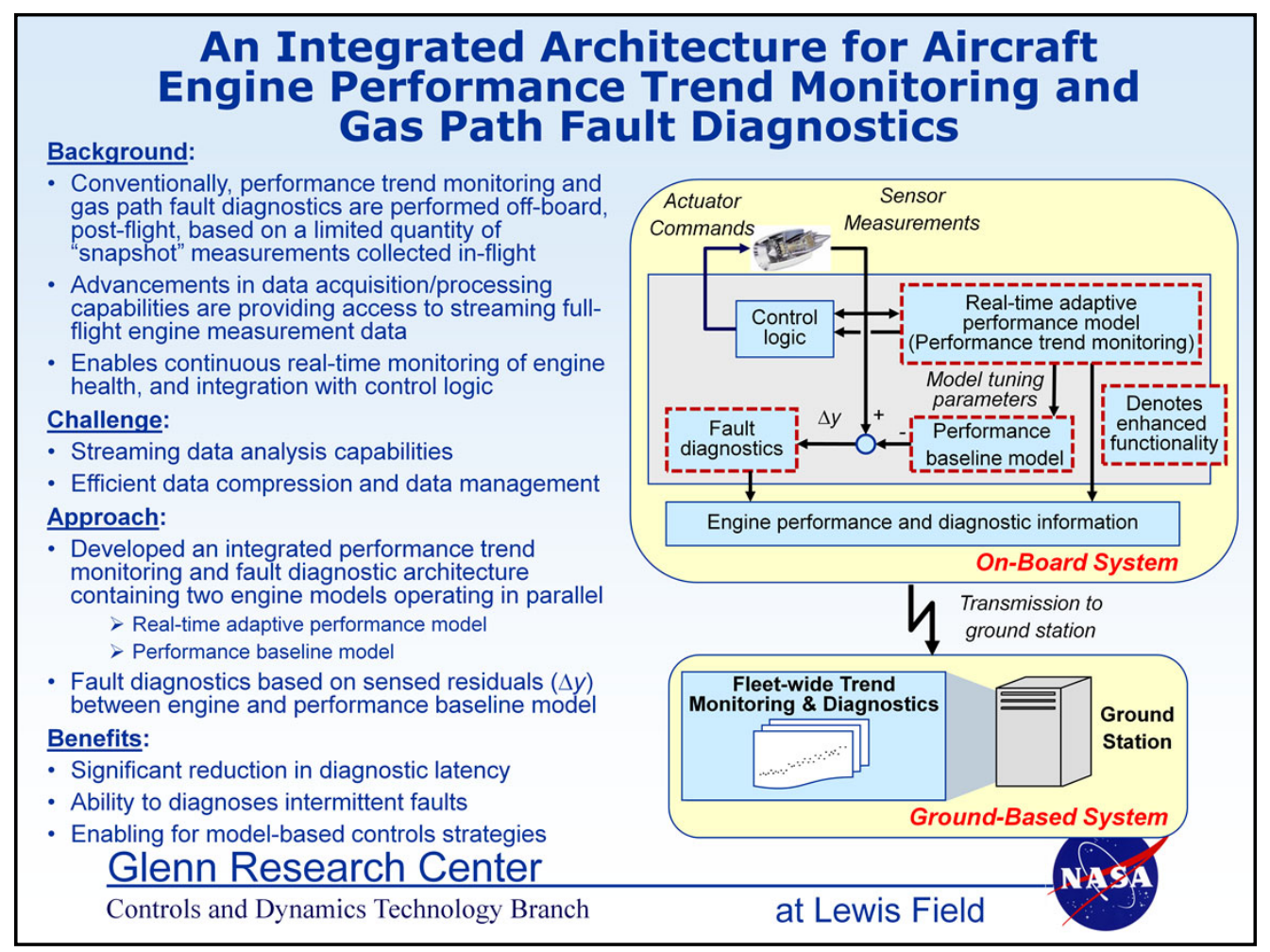

\section{An Integrated Architecture for Aircraft Engine Performance Trend Monitoring and Gas Path Fault Diagnostics}

Aircraft engine performance trend monitoring and gas path fault diagnostics are closely related technologies that assist operators in managing the health of their gas turbine engine assets. Trend monitoring is the process of monitoring the gradual performance change that an aircraft engine will naturally incur over time due to turbomachinery deterioration, while gas path diagnostics is the process of detecting and isolating the occurrence of any faults impacting engine flow-path performance. Today, these functions are conventionally performed based on the post-flight processing of a small number of engine snapshot measurements collected each flight. Often, this processing does not happen until several days after the flight has occurred causing significant diagnostic latency. Additionally, the resulting health information is only available off-board.

An enhanced architecture has been designed to address these limitations by migrating portions of the conventional ground-based functionality on-board. This is done to enable the real-time continuous monitoring of engine health, the earlier diagnosis of faults, and the estimation of unmeasured engine performance parameters that can be directly applied for on-board controls and health management applications. The architecture contains two engine models designed to operate in parallel. The first model, referred to as the real-time adaptive performance model (RTAPM), continuously self-tunes internal tuning parameters that allow it to match the performance level of the physical engine. Performance parameter estimates produced by the RTAPM can be used for controls purposes. The second model, referred to as the performance baseline model (PBM), serves as a baseline of recent past engine performance. Residuals between the engine and PBM outputs are analyzed for fault diagnostic purposes. The applicability of this approach for reliable fault detection and isolation with improved latency was demonstrated using a detailed engine dynamic simulation.

Ref.: Simon, D. L., "An Integrated Architecture for Onboard Aircraft Engine Performance Trend Monitoring and Gas Path Fault Diagnostics," NASA/TM-2010-216358, Proceedings of The 2010 JANNAF Joint Subcommittee Meeting, Colorado Springs, CO, May 3-7, 2010. 


\section{Vehicle Integrated Propulsion Research (VIPR)}

Ground-test Maturation of Engine Health Management (EHM) Technology

\author{
Background: \\ - NASA, in partnership with the U.S. Air Force and \\ Pratt \& Whitney, is conducting a series of on- \\ ground aircraft engine health management (EHM) \\ technology tests \\ - This series of tests is collectively referred to as \\ Vehicle Integrated Propulsion Research (VIPR) \\ Approach: \\ - A series of on-wing engine ground tests \\ conducted on a C-17 aircraft equipped with Pratt \\ \& Whitney F117 high-bypass turbofan engines \\ - Tests include "nominal" and "faulted" engine \\ operating scenarios \\ Model-Based Gas Path Health Management \\ Architecture: \\ - Architecture provides dual-functionality of \\ performance estimation and fault diagnostics \\ - VIPR testing enables evaluation of self-tuning \\ engine model's ability to track engine performance \\ - Insertion of gas path system faults (mis-scheduled \\ bleed valves) enables evaluation of gas path fault \\ detection and isolation capabilities
}

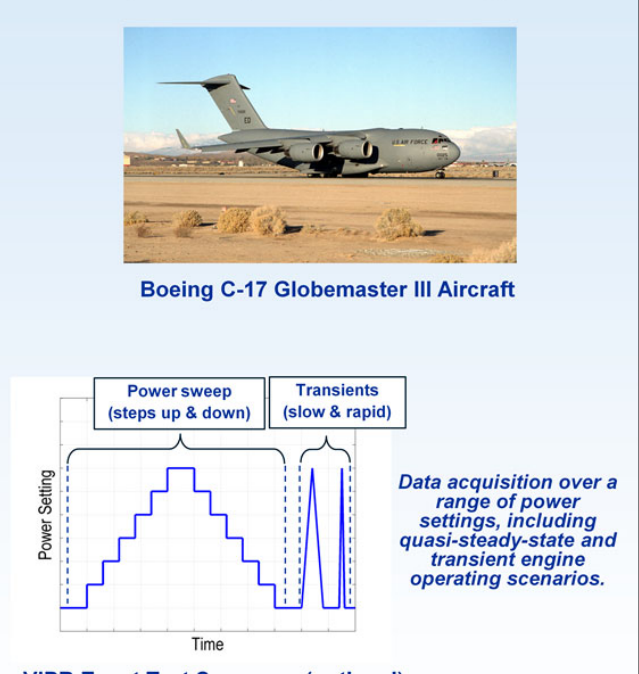

VIPR Event Test Sequence (notional)

\section{Vehicle Integrated Propulsion Research (VIPR)}

On-engine testing is a necessary component of aircraft Engine Health Management (EHM) technology development, required to demonstrate the technology against a known system "ground truth" state. However, the cost to conduct such testing is often prohibitive, making engine test opportunities rare. To address this need, NASA, working in collaboration with the U.S. Air Force and Pratt \& Whitney, is conducting a series of ground-based, onwing, engine tests of EHM technologies. This series of tests, referred to as Vehicle Integrated Propulsion Research (VIPR), is being conducted on a U.S. Air Force Boeing C-17 Globemaster III aircraft equipped with four Pratt \& Whitney F117 high bypass turbofan engines. The VIPR series of tests will include both "nominal" and "faulted" engine operating scenarios. The first VIPR test took place in 2011, and additional testing is planned for 2013 and 2014.

One of the NASA EHM technologies under test as part of VIPR is a model-based gas path health management architecture. This architecture consists of a self-tuning engine model and associated diagnostic logic designed to detect and isolate any gas path system faults. The self-tuning engine model includes a Kalman filter-based tracking filter that processes gas path sensor measurements and adjusts model tuning parameters to capture engine performance variations. The architecture's diagnostic logic continuously monitors for rapid or abrupt performance changes in the engine. If a performance change is detected, the diagnostic logic analyzes the observed change and classifies a root cause for the fault. Unlike conventional gas path health management methods that are primarily performed based on a limited number of snapshot measurements, the enhanced model-based gas path health management architecture enables the real-time processing of streaming measurement data. The benefits of this approach include real-time monitoring/trending of engine performance and the diagnosis of incipient gas path faults with reduced diagnostic latency. The VIPR testing is acquiring engine data at steady-state and transient operating scenarios, both when the engine is operating nominally and under known fault conditions. This provides actual engine data vital for evaluating and maturing the model-based gas path health management architecture. 


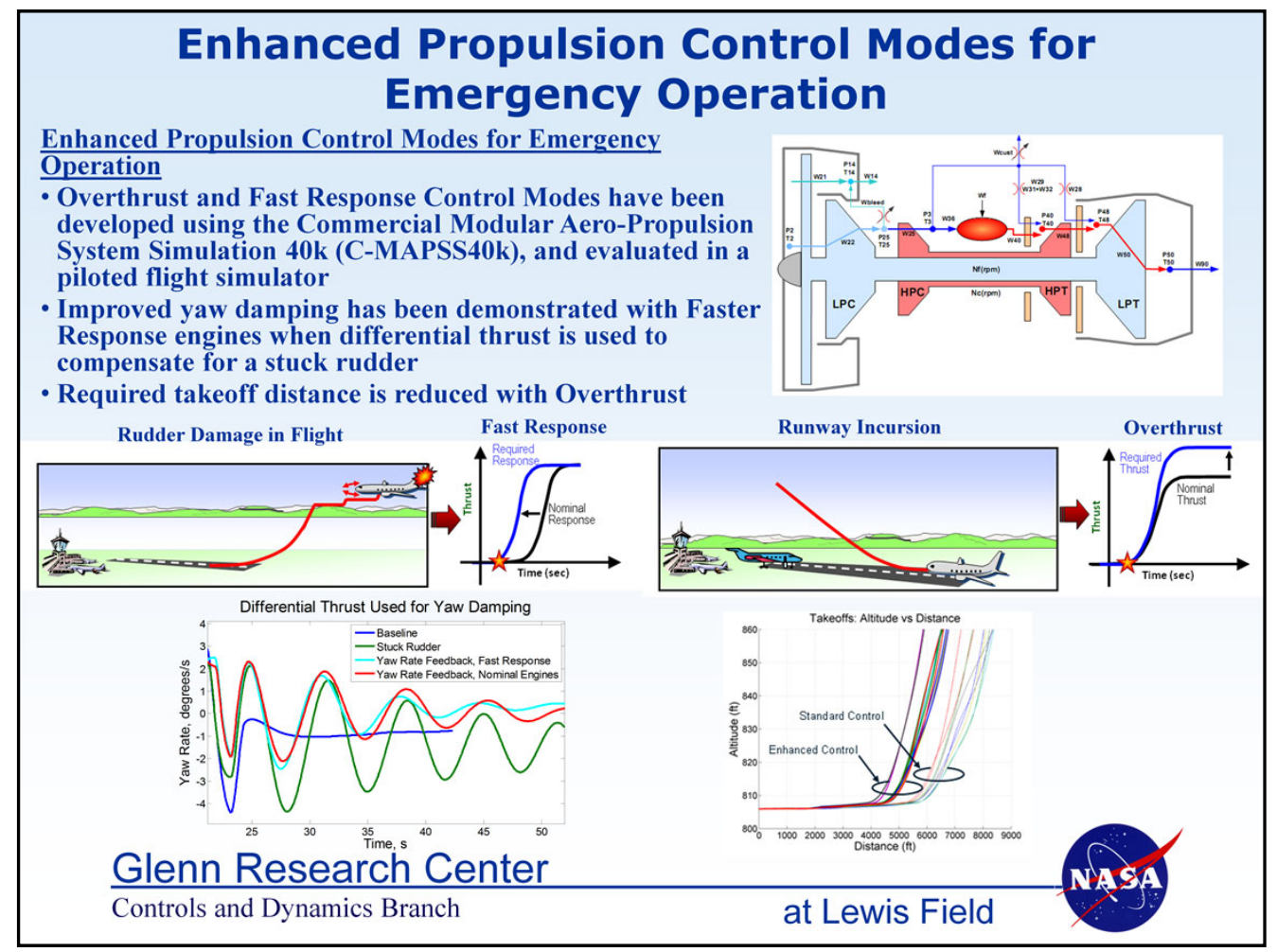

\section{Enhanced Propulsion Control Modes for Emergency Operation}

Previous in-flight emergencies in which flight control has been partially or totally lost, have required pilots to learn how to fly the damaged aircraft using the engines. Pilots have used differential thrust successfully for maneuvering on several occasions. Other examples of mid-air or on-the-ground crises, such as runway incursions or attempted take-offs from the wrong runway, have resulted in deadly accidents. However, it has been speculated that in some cases there is a potential safety improvement possible through the incorporation of additional propulsion system capability. For instance, it is possible to use differential thrust to replace or augment the function of a damaged rudder and vertical tail. However, the engine response is sluggish compared to traditional flight control, and their control moments tend to be relatively weak.

Research into achieving enhanced engine responsiveness to address these situations has revealed that the potential exists to greatly improve engine performance through control system modifications alone, albeit with a slightly increased risk to the engine. This risk is mitigated, however, by the overall safety improvement to the distressed vehicle. Enhanced propulsion control modes for emergency flight operation have been developed and demonstrated in simulation. Specifically, the two modes are Overthrust and Fast Response, which relate to emergency situations such as runway incursion and loss of flight control effectiveness, respectively. Piloted evaluation in a flight simulator has been performed using a full envelope nonlinear four-engine transport aircraft simulation. The incorporated engine model is the Commercial Modular Aero-Propulsion System Simulation 40k (CMAPSS40k) with realistically achievable enhanced propulsion control modes. Comparisons against the same aircraft/engine simulation utilizing a standard propulsion control have shown significant improvement in flight stability and control, and in reduced required takeoff distance for these emergency scenarios.

Ref: Litt, J.S., Sowers, T.S., Owen, A.K., Fulton, C., Chicatelli, A., "Flight Simulator Evaluation of Enhanced Propulsion Control Modes for Emergency Operation," AIAA 2012-2604, Infotech@Aerospace 2012, Garden Grove, CA, June 19-21, 2012. 


\section{Engine Icing: Simulation, Detection, and Mitigation \\ The Engine Icing Problem \\ - Ice crystals have been found to accrete in the engine compression system \\ - Accretion can lead to engine power-loss: \\ - Ice ingestion into combustor causing flameout \\ - Compressor surge \\ -Engine rollback \\ - 153 power-loss events identified from 1988-2010 \\ Modeling, Detection \& Mitigation \\ - Use C-MAPSS40k engine simulation \\ - LPC maps calculated for various blockage levels \\ - Rollback is caused by the engine controller limiting fuel when certain safety limits are reached \\ - Existing engine sensors have been shown to be capable of detecting accretion of ice at certain operating points \\ - Existing actuation can shift engine operating point to: - Lower shaft speeds (to prevent limit incursion) \\ - Alter airflow conditions (to prevent surge) \\ - Change temperatures in compressors (to prevent/melt accretion) \\ -Increase shaft speeds (to shed accumulated ice when small)

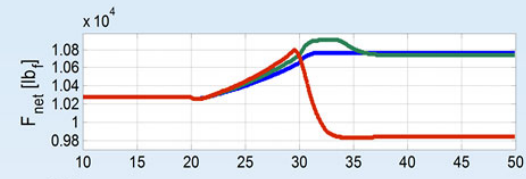 \\ Glenn Research Center \\ Controls and Dynamics Branch
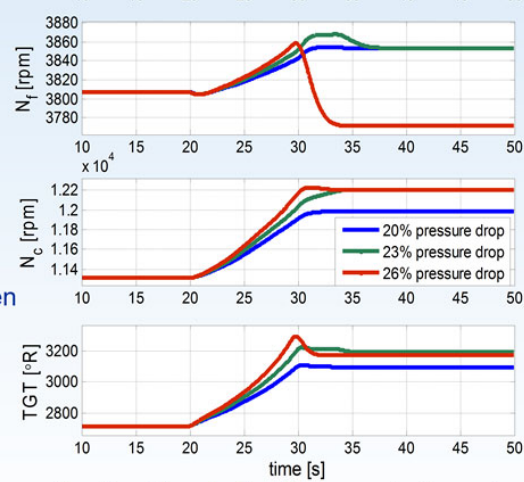 \\ Engine Simulation Demonstration of Thrust Rollback due to Coupling of Ice Accretion with Engine Control}

\section{Engine Icing: Simulation, Detection, and Mitigation}

Over the past 20 years, there have been over 200 reported cases of aircraft engine power loss due to the accretion of ice crystal particles in the compression system of commercial turbofan engines. The majority of the work in response to this aviation safety concern has focused on understanding the mechanism by which particles in high icewater content (HIWC) conditions can accrete on compressor stator blades, understanding the environmental conditions in which accretion can occur, and related regulatory guidance. While avoidance of HIWC conditions and compressor redesigns are the ideal long-term solutions, a systems level analysis highlights some near-term capabilities.

To this end, simulation studies were conducted using the C-MAPSS40k (Commercial Modular Aero-Propulsion System Simulation for a 40,000 lb thrust engine) engine model. Low Pressure Compressor maps that include the effect of blockage due to ice accretion were generated and integrated into the C-MAPSS40k simulation. Using this capability in conjunction with the realistic engine controller of C-MAPSS40k, research has shown that the engine rollback phenomenon is caused by the normal behavior of the engine controller responding to operational limits being encountered. As the ice accretion builds up, the decreased mass flow requires higher fan speed to maintain the commanded thrust, however, the engine controller limits the fuel flow to maintain the core speed at the maximum safe limit, resulting in a drop in the fan speed. This is the first known publicly available simulation demonstration that the observed thrust rollback is potentially caused due to the coupling of the engine control with the ice accretion effects. It was also shown that the change in engine performance associated with ice accretion can be detected by the existing sensor suite. When combined with the knowledge that the aircraft is operating in HIWC conditions, this could trigger the detection of ice accretion in the engine compression system. Future work seeks to determine various means of preventing ice accretion or mitigating the impact of the blockage.

Ref.: May, R.D., Guo, T-H., Veres J.P., Jorgenson, P.C.E., "Engine Icing Modeling and Simulation (Part 2): Performance Simulation of Engine Rollback Phenomena," 2011-38-0026, SAE International Conference on Aircraft and Engine Icing and Ground Deicing, Chicago, IL, Jun 13-17, 2011. 


\section{Integrated Flight and Propulsion Control}

Technical Challenge Problem

- Currently, flight control logic is designed separately from the propulsion control with the assumption that pilot integrates the propulsion system with flight control using the throttle

- An integrated approach to flight and propulsion control system design can provide enhanced performance capability which can potentially increase airplane safety dramatically by allowing the use of propulsion system as a flight control effector.

Research Objectives

- Specify and evaluate the full potential of integrated flight and propulsion control (IFPC) for enhanced flight safety

\section{Research Approach}

- Develop new integrated flight and propulsion controller architecture

- Develop control algorithms that can fully utilize the propulsion system as flight actuators with different response time

- Demonstrate the impact of new IFPC architecture on flight envelope protection and accommodation of simulated actuator failures - in simulation and in piloted evaluations of a flight simulator
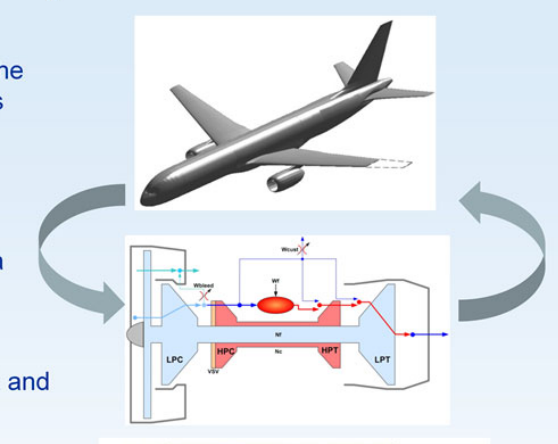
and

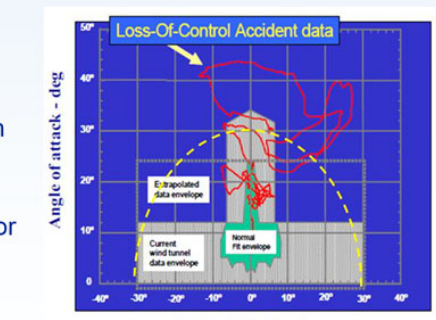

Angle of sideslip - deg

Glenn Research Center

Controls and Dynamics Branch at Lewis Field

\section{Integrated Flight and Propulsion Control}

The Vehicle System Safety Technologies (VSST) project under the Aviation Safety Program is tasked with developing, implementing and, validating advanced control systems for the safety of current and future aircraft flight operations. One of the challenging theme tasks under the VSST project is to address the "Loss-of-Control" of the aircraft. Since the propulsion system is one of the most powerful actuators for multi-engine aircraft, it is conceivable that an integrated flight and propulsion control (IFPC) system can be an effective way to control an aircraft to avoid entering an undesirable portion of the flight envelope or to help maneuver beyond the currently allowable envelope. Furthermore, under the previous Integrated Resilient Aircraft Control project of the Aviation Safety Program, research results showed that under certain conditions the engine can be operated with an enhanced response, both in terms of overthrust and faster thrust response, within a pre-defined risk of engine failure. This makes the integration of flight and propulsion control even more feasible for application.

However, the current flight and propulsion controllers are designed and operated separately. An integrated flight and propulsion control system can potentially increase the safety dramatically by utilizing propulsion system as a set of flight effectors. This research includes the evaluation of existing control theory analysis, specification of integration goals and requirements, assessment of the interactions of flight control and engine control, defining the interface between flight and propulsion control, and preliminary design demonstration of the integration of flight and propulsion control.

This is a joint research effort among NASA and its industry partners. 


\section{Engine Simulation Software Packages}

The following engine simulation software packages, developed in Matlab/Simulink and useful for propulsion controls and diagnostics research, are available from NASA GRC software repository

- MAPSS - Modular Aero-Propulsion System Simulation - Simulation of a modern fighter aircraft prototype engine with a basic research control law: http://sr.grc.nasa.gov/public/project/49/

- C-MAPSS - Commercial Modular Aero-Propulsion System Simulation - Simulation of a modern commercial 90,000 lb thrust class turbofan engine with representative baseline control logic: http://sr.grc.nasa.gov/public/project/54/

- C-MAPSS40k

- High fidelity simulation of a modern 40,000 lb thrust class turbofan engine with realistic baseline control logic:

http://sr.grc.nasa.gov/public/project/77/

Additionally, a one hour educational video on "Fundamentals of Aircraft Engine Control" is available at:

http://mediaexserver.larc.nasa.gov/Academy/SilverlightPlayer/Default.aspx?peid=135553bc3b7b4 171b7c54ee0578489211d

Glenn Research Center

Controls and Dynamics Branch at Lewis Field

\section{Engine Simulation Software Packages}

It is important to have access to publicly available realistic engine dynamic simulations to be able to perform meaningful engine control and diagnostics research. The Controls and Dynamics Branch has created various engine simulations in the Matlab/Simulink environment which are available to U.S. citizens for downloading from the NASA GRC software repository. This chart provides information on the various engine simulations that are available for download.

C-MAPSS40k, which is the latest in the suite of software packages, introduces a number of new features including an iterative solver and detailed compressor stall models. C-MAPSS40k also includes an "industry standard" controller for use as a baseline against which to compare new controllers and architectures. With these capabilities, users in academia, industry, and government have access to a generic, high-fidelity engine simulation that can be used to quickly develop, simulate, and test new control system components and architectures, and diagnostic algorithms. C-MAPSS40k is being used extensively by NASA researchers in support of the Aviation Safety and Fundamental Aeronautics Programs research efforts, and by our industry partners for NASA sponsored as well as internal research efforts.

Also, recently, the author recorded a 1 hour video on "Fundamentals of Aircraft Engine Control" as part of the NASA Engineering and Safety Center (NESC) web lecture series on Guidance, Navigation and Control applications across NASA programs. This lecture is available as indicated, and provides a good overview for students in the senior level propulsion class as well as controls engineers interested in pursuing research in engine control and diagnostics.

Ref: May, R. D., Csank, J. T., Lavelle, T. M., Litt, J. S., Guo, T. -H., “A High-Fidelity Simulation of a Generic Commercial Aircraft Engine and Controller," Joint Propulsion Conference, Nashville, TN, July 25-28, 2010. 


\section{$3^{\text {rd }}$ GRC Propulsion Control and Diagnostics Workshop Feb. 28 - Mar. 1, 2012, Cleveland, $\mathrm{OH}$.}

- Workshop Objectives:

- Disseminate information to the research community about the propulsion control and diagnostics research being done at NASA GRC in support of various projects under the NASA Aeronautics Research Mission Directorate (ARMD) programs.

- Get feedback on value of the research and validity of technical approach.

- Identify opportunities for potential collaboration and sharing of tools and methods.

- Workshop Content:

- Overview presentations on PCD research at NASA, DoD and Engine Companies.

- Detailed presentations on the GRC PCD research efforts - progress to date and future plans, and tools and simulations available for public use.

- Plenary speakers during lunch and reception providing broader perspective on Propulsion research - NASA SFW project, Boeing, MTU (Germany).

- One-on-one discussions between NASA researchers and attendees

- Presentations available at:

$$
\text { http://www.grc.nasa.gov/WWW/cdtb/index.html }
$$

- Over 65 attendees with heavy participation from Industry. Overall extremely positive feedback.

\section{Glenn Research Center}

\section{$3^{\text {rd }}$ GRC Propulsion Control and Diagnostics Workshop}

The $3^{\text {rd }}$ GRC PCD (Propulsion Control and Diagnostics) Workshop was held on February 28 to March 1, 2012, at the Ohio Aerospace Institute, Cleveland, Ohio. The objectives of the workshop were to: Disseminate information to the research community about the propulsion control and diagnostics research being done at by RHC (Controls and Dynamics Branch) in support of various projects under the NASA Aeronautics Research Mission Directorate (ARMD) programs; Get feedback from peers on value of the research and validity of the technical approach; and Identify opportunities for potential collaboration and sharing of tools and methods.

The workshop consisted of: Overview presentations on ongoing research in aircraft engine control and diagnostics at NASA, DoD (Department of Defense) and Engine manufacturers; Detailed presentations on the RHC PCD research efforts - progress to date and future plans, and tools and simulations available for public use; and One-onone discussions between NASA researchers and attendees to answer any questions and identify potential collaboration opportunities. There were over 65 attendees from academia, industry and government with a large portion being from the industry. The feedback from the attendees has been extremely positive in terms of the workshop meeting the stated objectives and the opportunity it provides for networking within the aero-propulsion control and diagnostics research community.

The presentations from the workshop are available at the CDB website as indicated in the chart above. Below is a sample of overall feedback provided by some of the attendees:

- "I learned quite a bit from the workshop and found it very valuable" - Industry Participant

- "Covered a lot of material, did it concisely, little wasted time" - Industry Participant

- "This was an essential and extremely valuable workshop with highly relevant and high quality presentations. The high regard with which industry value this event is indicated by the large number of attendees. Well done!" - Small Business Participant 


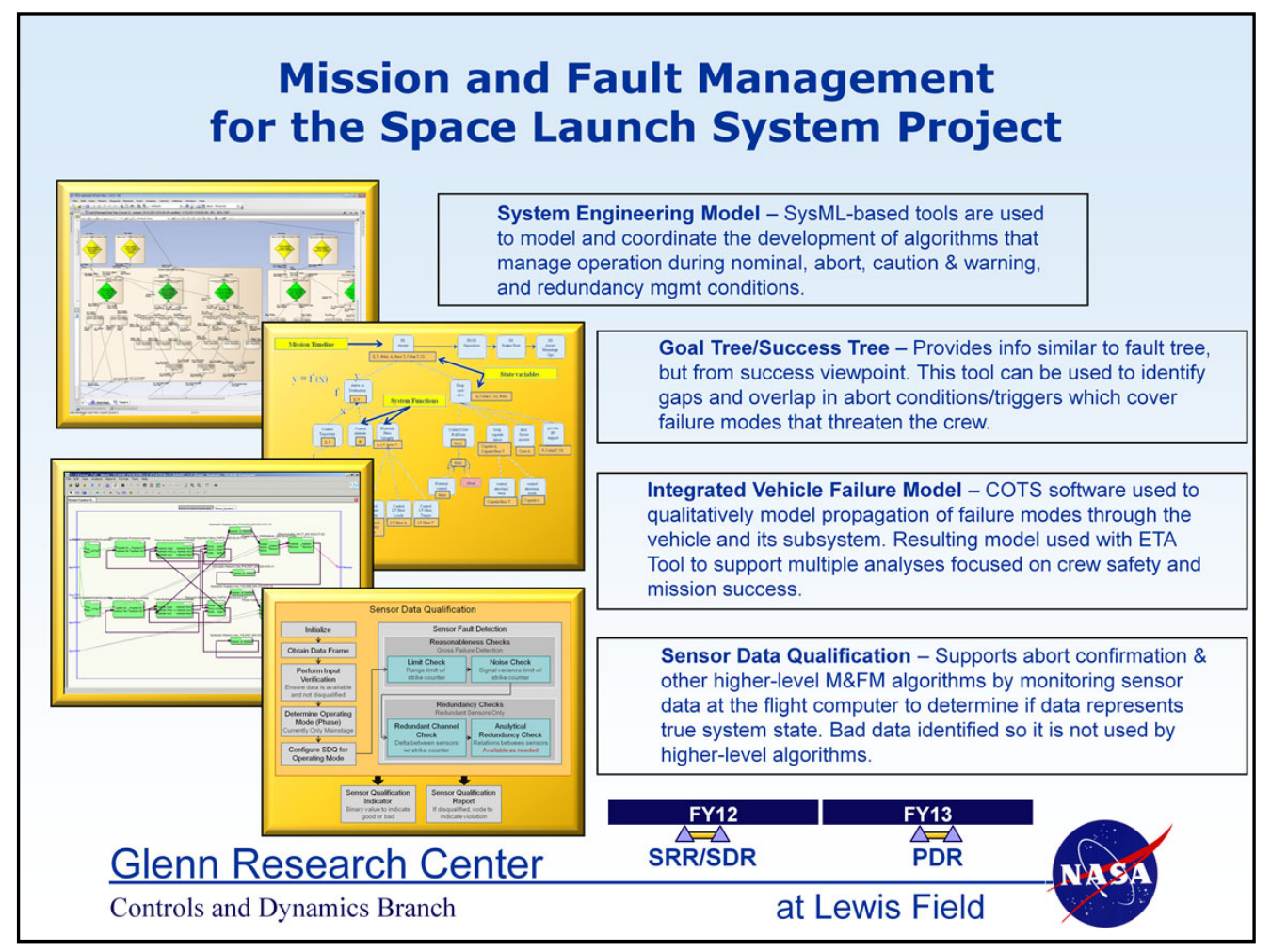

\section{Mission and Fault Management for the SLS Project}

NASA's Space Launch System Project (SLS) is a contractor build with government oversight/insight effort. NASA Glenn currently supports SLS systems engineering and integration under a sub-project known as Mission and Fault Management (M\&FM). M\&FM is responsible for developing analyses and algorithms for normal operation, abort conditions, caution \& warning situations, and redundancy management — efforts that are focused first on ensuring crew safety/survival and secondly on ensuring mission success. In these areas, NASA Glenn covers the vehicle's Thrust Vector Control (TVC) and Electrical Power System (EPS) subsystems. Early M\&FM efforts have been focused on identifying and developing required capabilities and processes. The SLS Project completed a System Requirements and System Definition Review in the March-April 2012 timeframe and is currently working toward a Preliminary Design Review. NASA Glenn is currently working the four areas shown here:

- Goal Tree/Success Tree (GT/ST) - Responsible for developing a GT/ST for the entire Core Stage ascent phase. As planned, the GT/ST will be used early in the design process to identify gaps and overlap in abort conditions/triggers which cover failure modes that threaten the crew.

- System Engineering Model-New SysML-based tools are being used to model and coordinate the development of M\&FM algorithms with subsystem designers and the flight software team.

- Integrated Vehicle Failure Model-This model seeks to capture the propagation of faults through SLS systems, subsystems, and components. Early models are qualitative and can be used to determine whether or not designs meet requirements for fault management. This allows for changes to be made earlier in the design process when changes are less costly.

- Sensor Data Qualification-Monitors data from flight critical sensors at the flight computer to determine if they reflect the true system state. Uses multiple algorithms and persistence to minimize the probability of a false positive or false negative detection. Bad data is flagged so that it is not used by higher-level M\&FM algorithms. 


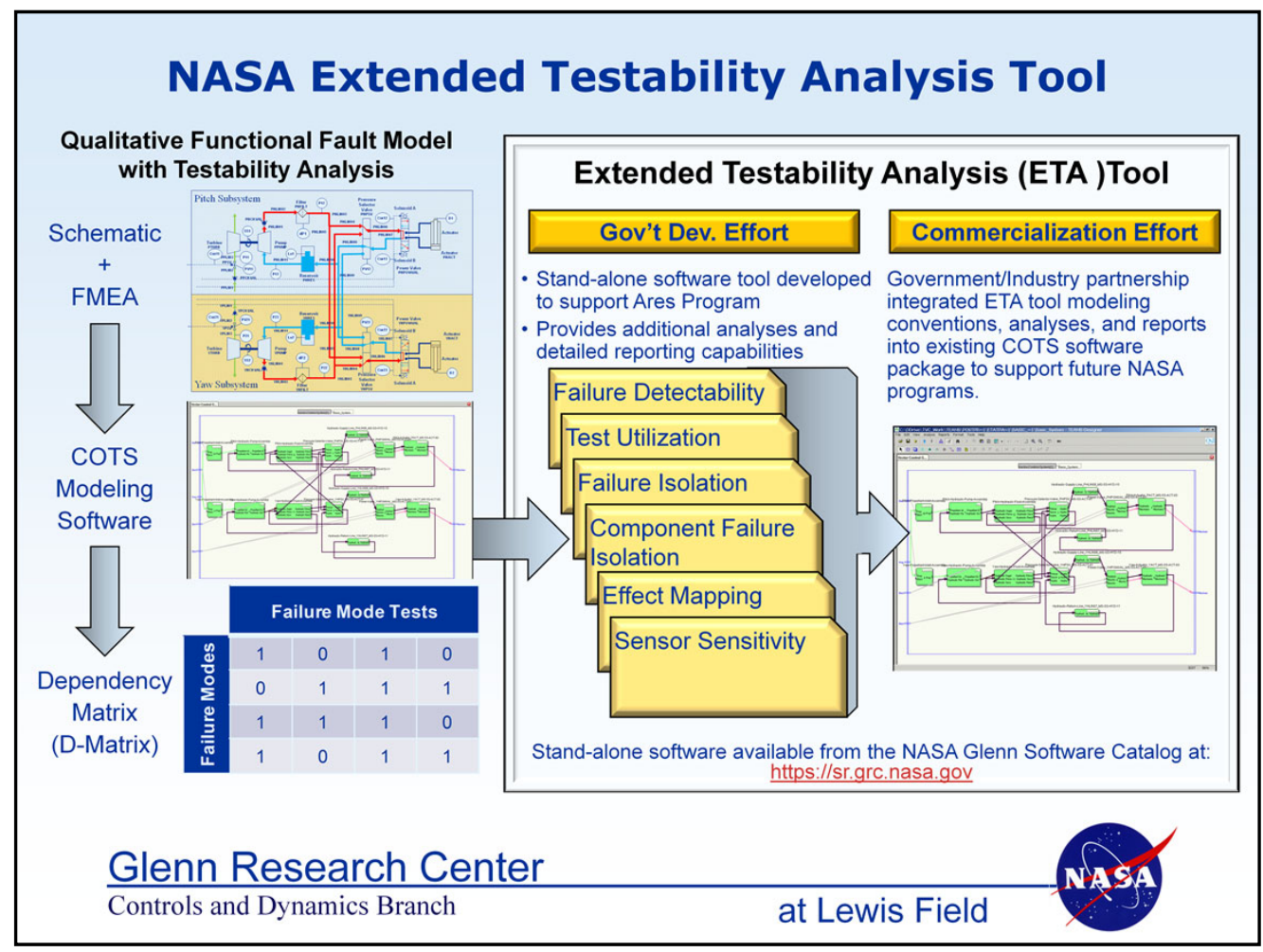

\section{NASA Extended Testability Analysis Tool}

During the Ares I Upper Stage (US) Project, Functional Fault Models (FFMs) and testability analyses provided significant new capabilities for assessing the ability of early US designs to meet requirements for fault detection and isolation. Design schematics and Failure Modes and Effects Analyses (FMEA) were used as the basis for creating FFMs of the US subsystems in COTS modeling software. The COTS software provides a graphical framework for capturing the design architecture shown in system schematics; the failure modes associated with systems components; and the way the failure modes propagate from one subsystem or component to another. The COTS software generates a Dependency Matrix (D-Matrix) which maps each failure mode to the set of sensor-based logical tests that are available for detecting the failure modes.

The ETA Tool was developed under the Ares I US project as stand-alone software tool that extends the testability analysis and reporting capabilities provided by the COTS modeling software. The ETA Tool uses the COTS model information and the D-MATRIX to determine: overlap or gaps in the detection of failure modes; tests that are not useful for detecting faults; if failure modes can be isolated via unique detection signatures; whether failure modes originating in a specific component can be isolated to that component; and failure modes that cannot be detected if a given sensor fails.

Having seen the capabilities of the ETA Tool, the COTS software vendor expressed interest in integrating those capabilities into the COTS software. A government/industry partnership was subsequently implemented to conduct the integration. ETA Tool capabilities are now available as part of the COTS tool and also as a stand-alone software package through the NASA Glenn software catalog.

Ref.: Maul, William, A.; Fulton, Christopher, E., "Software Users Manual (SUM): Extended Testability Analysis (ETA) Tool”, NASA/CR-2011-217240, November 2011. 


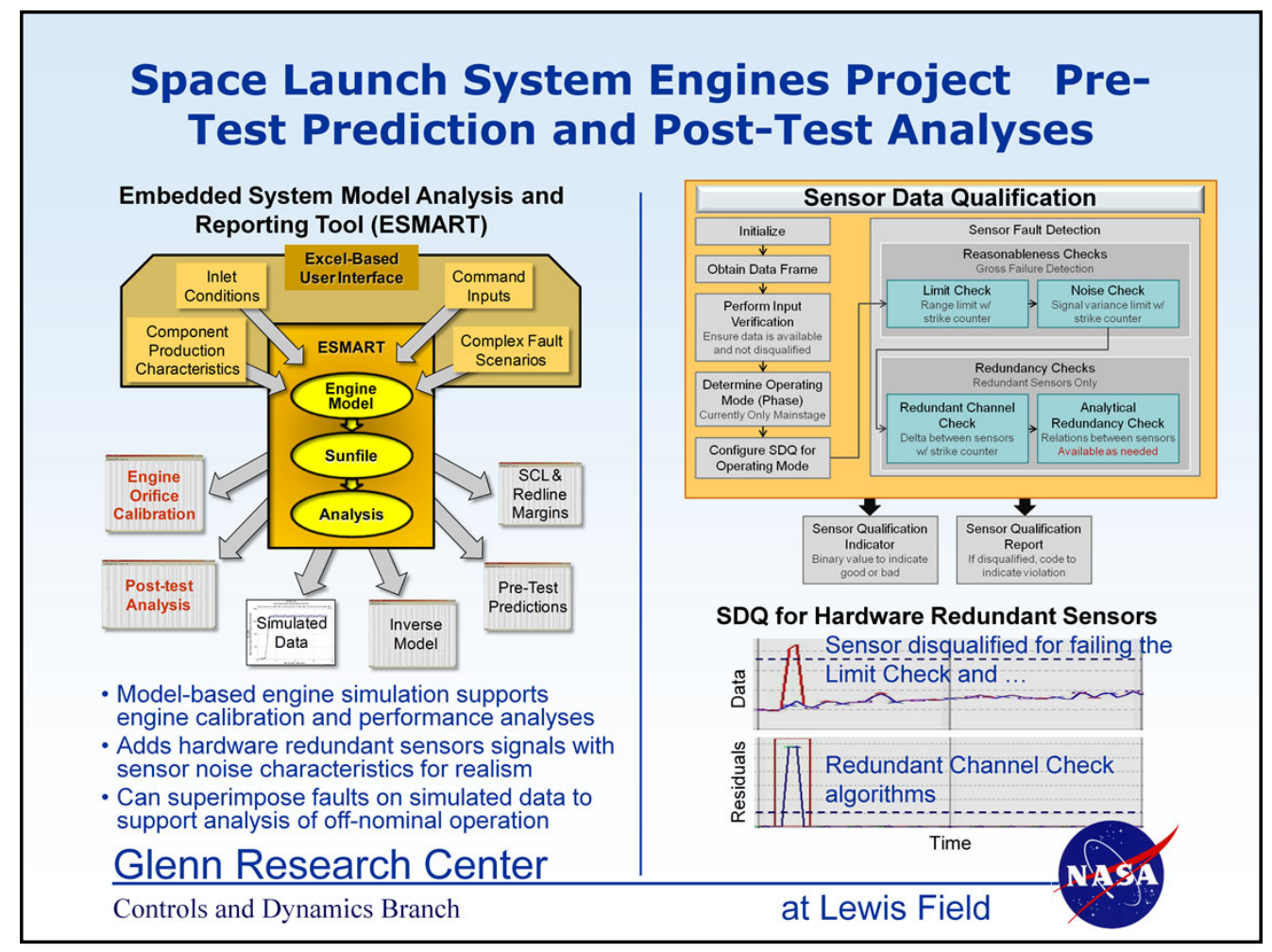

\section{SLS Engines Project Pre-Test Prediction and Post-Test Analysis}

NASA Glenn support for the SLS Engine Project is focused on developing analytical approaches to predict engine performance prior to testing and to analyze test data to support post test review.

ESMART (Embedded System Model Analysis and Reporting Tool) is a software simulation tool that is being developed to provide pre-test predictions of the J-2X engine and J-2X PowerPack. To generate pre-test predictions, an engine model with a mixture of physics-based and empirical equations is used. This simulation is capable of modeling both nominal and off-nominal operation. The initial data is then expanded by capturing hardware redundancy of the sensors and adding stochastically-based sensor noise characteristics for realism. A spreadsheetbased user interface provides a convenient mechanism for setting up the simulation/analysis. Results are generated in a format for compatibility with analysis tools like WinPlot. ESMART is currently being used to support the definition of test conditions and the selection of the red-line limits needed to protect the engine.

An important element of post-test analysis of the engine data is understanding the health of the individual sensors. NASA Glenn Sensor Data Qualification (SDQ) algorithms are being used to analyze J-2X test data for faulty sensors. SDQ algorithms analyze signal and noise levels, and compare responses of hardware redundant sensors or heterogeneous sensors to identify those sensors that do not accurately reflect the physical state of the engine. A multi-algorithm approach and phase-dependent thresholds reduce the likelihood of false alarms. Results are captured in spreadsheet form where failed sensor signal information is detailed. Additionally, SDQ generates a WinPlot script that plots time traces for the failed sensor signals which allow experts to visually confirm the SDQ results.

The work discussed here has been initiated in the last couple of years and there are no publications yet on this work. Information on prior J-2X modeling effort is available in the reference listed below.

Ref: Sowers, T., Santi, L., Butas, J., "Selection of Sensors for J-2X Test Data Reduction", IPS-I-04, 54 th JANNAF Propulsion Meeting, Orlando, Florida, December 8-12, 2008. 


\section{Concluding Remarks}

- The Controls and Dynamics Branch (CDB) is conducting cutting edge research in propulsion control and diagnostics in support of NASA Aeronautics Research and Human Exploration and Operations Missions.

- The various controls and health management technologies being developed by CDB in collaboration with industry and academia partners will help improve aviation safety and increase fuel efficiency while helping meet challenging emission reduction goals, and will enable safer and more efficient operation of the Space Launch System.

- Multidisciplinary cross-organizational collaboration and a system level approach are essential for successful development, demonstration and transition of Intelligent Propulsion System technologies.

\section{Glenn Research Center}

Controls and Dynamics Branch at Lewis Field

\section{Concluding Remarks}

The Controls and Dynamics Branch (CDB) at NASA Glenn Research Center is working in strong partnership with industry, academia and other government agencies to develop the propulsion control and health management technologies that will help meet NASA's Aeronautics Research Mission and Human Exploration and Operations Mission objectives. For the Aeronautics Research Mission, CDB is conducting research in: Distributed Engine Control architectures and technologies development, Model-Based Engine Control, Active Combustion Control, and High Speed Propulsion System Dynamic Modeling and Control, to help meet the objectives of the Fundamental Aeronautics Program; Gas Path Health Management, Enhanced Engine Response Control, and Robust Propulsion Control to help meet the goals of the Aviation Safety Program; and health management technologies development to help meet the challenge for safe and efficient operation of the Space Launch System.

Our aim is to use the public resources in a most efficient manner to make a significant contribution to the aggressive goals that have been set by the administrator in the latest strategic plan for NASA, and to ensure that our activities are aligned with the goals of the NASA Missions that we participate in. We take a systems level approach to ensure that the various components of a control or diagnostic system work together as an integrated system to achieve the desired objectives. CDB also actively pursues opportunities to disseminate information on our technology development efforts to the aerospace research community by presenting papers at technical conferences, holding the GRC Propulsion Control and Diagnostics Workshop on a bi-annual basis, and making available various software tools for enabling advanced research in propulsion control and diagnostics. 



\begin{tabular}{|c|c|c|}
\hline \multicolumn{2}{|c|}{ REPORT DOCUMENTATION PAGE } & $\begin{array}{l}\text { Form Approved } \\
\text { OMB No. 0704-0188 }\end{array}$ \\
\hline \multicolumn{3}{|c|}{ 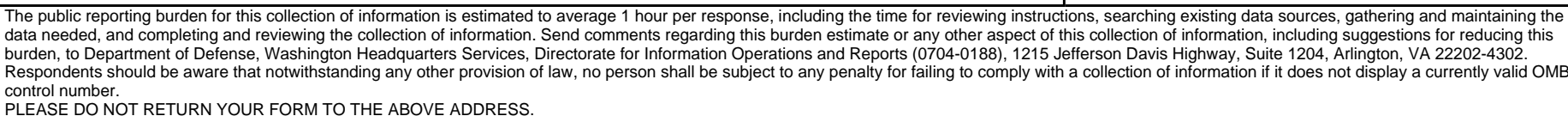 } \\
\hline $\begin{array}{l}\text { 1. REPORT DATE (DD-MM-YYYY) } \\
01-10-2012\end{array}$ & $\begin{array}{l}\text { 2. REPORT TYPE } \\
\text { Technical Memorandum }\end{array}$ & 3. DATES COVERED (From - To) \\
\hline \multirow{3}{*}{\multicolumn{2}{|c|}{$\begin{array}{l}\text { 4. TITLE AND SUBTITLE } \\
\text { Overview of Propulsion Controls and Diagnostics Research at NASA Glenn }\end{array}$}} & 5a. CONTRACT NUMBER \\
\hline & & 5b. GRANT NUMBER \\
\hline & & 5c. PROGRAM ELEMENT NUMBER \\
\hline \multirow{3}{*}{\multicolumn{2}{|c|}{$\begin{array}{l}\text { 6. AUTHOR(S) } \\
\text { Garg, Sanjay }\end{array}$}} & 5d. PROJECT NUMBER \\
\hline & & 5e. TASK NUMBER \\
\hline & & $\begin{array}{l}\text { 5f. WORK UNIT NUMBER } \\
\text { WBS 432938.11.01.03.02.02.15 }\end{array}$ \\
\hline \multicolumn{2}{|c|}{$\begin{array}{l}\text { 7. PERFORMING ORGANIZATION NAME(S) AND ADDRESS(ES) } \\
\text { National Aeronautics and Space Administration } \\
\text { John H. Glenn Research Center at Lewis Field } \\
\text { Cleveland, Ohio 44135-3191 }\end{array}$} & $\begin{array}{l}\text { 8. PERFORMING ORGANIZATION } \\
\text { REPORT NUMBER } \\
\text { E-18429 }\end{array}$ \\
\hline \multirow{2}{*}{\multicolumn{2}{|c|}{$\begin{array}{l}\text { 9. SPONSORING/MONITORING AGENCY NAME(S) AND ADDRESS(ES) } \\
\text { National Aeronautics and Space Administration } \\
\text { Washington, DC 20546-0001 }\end{array}$}} & $\begin{array}{l}\text { 10. SPONSORING/MONITOR'S } \\
\text { ACRONYM(S) } \\
\text { NASA }\end{array}$ \\
\hline & & $\begin{array}{l}\text { 11. SPONSORING/MONITORING } \\
\text { REPORT NUMBER } \\
\text { NASA/TM-2012-217718 }\end{array}$ \\
\hline \multicolumn{3}{|c|}{$\begin{array}{l}\text { 12. DISTRIBUTION/AVAILABILITY STATEMENT } \\
\text { Unclassified-Unlimited } \\
\text { Subject Categories: } 07 \text { and } 63 \\
\text { Available electronically at http://www.sti.nasa.gov } \\
\text { This publication is available from the NASA Center for AeroSpace Information, 443-757-5802 }\end{array}$} \\
\hline
\end{tabular}

\section{SUPPLEMENTARY NOTES}

\section{ABSTRACT}

With the increased emphasis on aircraft safety, enhanced performance and affordability, and the need to reduce the environmental impact of aircraft, there are many new challenges being faced by the designers of aircraft propulsion systems. The Controls and Dynamics Branch (CDB) at NASA (National Aeronautics and Space Administration) Glenn Research Center (GRC) in Cleveland, Ohio, is leading and participating in various projects in partnership with other organizations within GRC and across NASA, the U.S. aerospace industry, and academia to develop advanced controls and health management technologies that will help meet these challenges through the concept of an Intelligent Engine. CDB conducts propulsion control and diagnostics research in support of various programs and projects under the NASA Aeronautics Research Mission Directorate and the Human Exploration and Operations Mission Directorate. The paper first provides an overview of the various research tasks in CDB relative to the NASA programs and projects, and briefly describes the progress being made on each of these tasks. The discussion here is at a high level providing the objectives of the tasks, the technical challenges in meeting the objectives and most recent accomplishments. References are provided for each of the technical tasks for the reader to familiarize themselves with the details.

\section{SUBJECT TERMS}

Turbofan engines; Sensors; Actuators; Fault detection; Engine control

\begin{tabular}{|c|c|c|c|c|c|}
\hline \multicolumn{3}{|c|}{ 16. SECURITY CLASSIFICATION OF: } & \multirow{2}{*}{$\begin{array}{l}\text { 17. LIMITATION OF } \\
\text { ABSTRACT } \\
\text { UU }\end{array}$} & \multirow{2}{*}{$\begin{array}{l}\text { 18. NUMBER } \\
\text { OF } \\
\text { PAGES } \\
32\end{array}$} & \multirow{2}{*}{$\begin{array}{l}\text { 19a. NAME OF RESPONSIBLE PERSON } \\
\text { STI Help Desk (email:help@sti.nasa.gov) } \\
\text { 19b. TELEPHONE NUMBER (include area code) } \\
\text { 443-757-5802 }\end{array}$} \\
\hline $\begin{array}{l}\text { a. REPORT } \\
U\end{array}$ & $\begin{array}{l}\text { b. ABSTRACT } \\
U\end{array}$ & $\begin{array}{l}\text { c. THIS } \\
\text { PAGE } \\
\text { U }\end{array}$ & & & \\
\hline
\end{tabular}



